\title{
Alterations of the acylcarnitine profiles in blood serum and in muscle from periparturient cows with normal or elevated body condition
}

\author{
Morteza H. Ghaffari, ${ }^{1 *}$ Hassan Sadri, ${ }^{2 *} \dagger$ Katharina Schuh,,${ }^{1,3}$ Georg Dusel, ${ }^{3}$ Cornelia Prehn, ${ }^{4}$ \\ Jerzy Adamski, ${ }^{4,5,6}$ Christian Koch, ${ }^{7}$ and Helga Sauerwein ${ }^{1} \ddagger$ \\ ${ }^{1}$ Institute of Animal Science, Physiology \& Hygiene Unit, University of Bonn, 53115 Bonn, Germany \\ ${ }^{2}$ Department of Clinical Science, Faculty of Veterinary Medicine, University of Tabriz, 516616471 Tabriz, Iran \\ ${ }^{3}$ Department of Life Sciences and Engineering, Animal Nutrition and Hygiene Unit, University of Applied Sciences Bingen, \\ 55411 Bingen am Rhein, Germany \\ ${ }^{4}$ Research Unit Molecular Endocrinology and Metabolism, Genome Analysis Center, Helmholtz Zentrum München, \\ German Research Center for Environmental Health, Neuherberg 85764, Germany \\ ${ }^{5}$ Lehrstuhl für Experimentelle Genetik, Technische Universität München, Freising-Weihenstephan 85350, Germany \\ ${ }^{6}$ Department of Biochemistry, Yong Loo Lin School of Medicine, National University of Singapore, 8 Medical Drive, Singapore 117597, Singapore \\ ${ }^{7}$ Educational and Research Centre for Animal Husbandry, Hofgut Neumuehle, 67728 Muenchweileran der Alsenz, Germany
}

\begin{abstract}
The objective of the current study was to characterize muscle and blood serum acylcarnitine (AcylCN) profiles and to determine the mRNA abundance of muscle carnitine acyltransferases in periparturient dairy cows with high (HBCS) and normal body condition (NBCS). Fifteen weeks antepartum, 38 pregnant multiparous Holstein cows were assigned to 2 groups that were fed differently to reach the targeted BCS and backfat thickness (BFT) until dry-off at $-49 \mathrm{~d}$ before calving (HBCS: BCS $>3.75$ and BFT $>1.4 \mathrm{~cm}$; NBCS: $<3.5$ and $<1.2 \mathrm{~cm}$ ). Thereafter, both groups were fed identical diets. Blood samples and biopsies from the semitendinosus muscle were collected on d $-49,3,21$, and 84 relative to calving. Actual BCS at d -49 were $3.02 \pm 0.24$ and $3.82 \pm 0.33$ (mean $\pm \mathrm{SD}$ ) for NBCS and HBCS, respectively. In both groups, serum profiles showed marked changes during the periparturient period, with decreasing concentrations of free carnitine and increasing concentrations of long-chain AcylCN. Compared with NBCS, HBCS had greater serum longchain AcylCN in early lactation, which may point to an insufficient adaptation of their metabolism in response to the metabolic load of fatty acids around parturition. The muscle concentrations of $\mathrm{C}_{-}-, \mathrm{C} 9-, \mathrm{C} 18: 1-$, and C18:2-AcylCN were lower and those of C14:2-AcylCN were greater in HBCS than in NBCS cows. The mRNA
\end{abstract}

Received October 7, 2019.

Accepted December 19, 2019.

*These authors contributed equally to this work.

$\dagger$ H. Sadri was a visiting scientist at the Institute of Animal Science, Physiology and Hygiene Unit, University of Bonn, 53115 Bonn, Germany at the time the research was done.

‡Corresponding author: sauerwein@uni-bonn.de abundance of carnitine palmitoyltransferase (CPT)1, muscle isoform $(C P T 1 b)$ and CPT2 increased from $\mathrm{d}$ -49 to early lactation (d 3, d 21), followed by a decline to nearly antepartum values by d 84 ; this change was not affected by group. In conclusion, over-conditioning around calving seems to be associated with mitochondrial overload, which can result in incomplete fatty acid oxidation in dairy cows.

Key words: carnitine palmitoyltransferase, acylcarnitine, body condition score, transition cow

\section{INTRODUCTION}

The adaptation to the metabolic changes during the transition from late gestation to early lactation carries some risks for metabolic disorders in dairy cows postpartum (pp) (Drackley et al., 2005). With the onset of lactation, voluntary feed intake decreases and the need for energy rises rapidly to support milk production; these changes often induce metabolic stress and immunological disturbances in dairy cows (Kinoshita et al., 2018). The ability to cope with metabolic stress imposed by early lactation depends on energy-generating pathways such as mitochondrial fatty acid oxidation (FAO) and the tricarboxylic acid (TCA) cycle (Dechow et al., 2004; Ospina et al., 2010), which are crucial for energy metabolism (McCoin et al., 2015) and thus for metabolic efficiency in dairy cows (Kinoshita et al., 2018).

Over-conditioned cows at parturition are less able to adapt their metabolism to lactation than cows in normal body condition (Schulz et al., 2014). Incomplete oxidation of long-chain fatty acids (LCFA) due to impaired activity of carnitine palmitoyltransferase (CPT) or to a depletion of TCA cycle intermediates may increase the concentrations of long-chain acylcarnitines (AcylCN; Flanagan et al., 2010; Schooneman 
et al., 2013), indicating defects in FAO (Ramos-Roman et al., 2012). Acylcarnitines are incompletely oxidized intermediates in the oxidation of fatty acids (FA) and AA that can be synthesized by both mitochondrial and peroxisomal enzymes. The carnitine shuttle transfers FA from the cytosol to the inner mitochondrial membrane for oxidation, and this transport system is regulated by carnitine acyltransferases, including CPT1 and CPT2 (Flanagan et al., 2010; Schooneman et al., 2013). Thus, circulating AcylCN profile reflects the oxidation rate of $\mathrm{FA}$ and $\mathrm{AA}$ in different tissues, mainly skeletal muscle and liver (Xu et al., 2011; Schooneman et al., 2013; Makrecka-Kuka et al., 2017). Short-chain AcylCN are mainly synthesized from AA and FA, whereas medium- and long-chain AcylCN are derived exclusively from FAO (Makrecka-Kuka et al., 2017). Elevated long-chain AcylCN concentrations in blood have been observed in obese humans with insulin resistance (Schooneman et al., 2016). Likewise, in overconditioned dairy cows, long-chain AcylCN have been reported to increase around parturition (Rico et al., 2018), supporting the notion of excessive lipolysis and incomplete $\mathrm{FAO}$ in these animals.

However, less is known about changes in free carnitine and AcylCN concentrations in skeletal muscle, one of the dominating tissues in FA uptake, of over-conditioned cows at the onset of lactation. Herein, we used an animal model in which dairy cows differing in body condition around calving were obtained for studying different intensities of lipo-mobilization around calving (Schuh et al., 2019). Focusing on the potential relationship between AcylCN metabolism and FAO, we aimed to elucidate (1) the alterations in the concentrations of AcylCN in serum and skeletal muscle of Holstein cows that are either over-conditioned or have normal body condition; and (2) the modification of mRNA abundance of CPT1, muscle isoform (CPT1b) and CPT2 in skeletal muscle related to body condition and time during the periparturient period. As the concentrations of various AcylCN are associated with impaired mitochondrial FAO in mice (Bjørndal et al., 2018), we hypothesized that serum and muscle AcylCN profiling would yield metabolite patterns reflecting impaired FAO in over-conditioned cows experiencing excessive lipolysis.

\section{MATERIALS AND METHODS}

\section{Animals, Group, and Experimental Design}

The experiment was conducted at the Educational and Research Centre for Animal Husbandry, Hofgut Neumuehle, Muenchweiler a.d. Alsenz, Germany. All animal experiments were performed according to the German Animal Welfare Act and approved by the local authority for animal welfare affairs (Landesuntersuchungsamt Rheinland-Pfalz; G 14-20-071) in Koblenz, Germany.

The basic setup of the trial with performance results, data of "classical" variables, and metabolome assessed in blood serum was described by Schuh et al. (2019) and Ghaffari et al. (2019). In brief, 38 multiparous German Holstein cows (parity: $2.5 \pm 0.5$, mean $\pm \mathrm{SD}$ ) were allocated $15 \mathrm{wk}$ before their anticipated calving date to either the normal body condition (NBCS; $\mathrm{n}=19$, parity: $2.42 \pm 1.84$; BW: $665 \pm 64 \mathrm{~kg}$, mean $\pm \mathrm{SD})$ or the high body condition (HBCS; $\mathrm{n}=19$, parity: 3.37 \pm 1.67 ; BW: $720 \pm 57 \mathrm{~kg}$ ) group (Figure 1a). These 2 groups were fed differently (for diets, see Supplemental Table S1; https://doi.org/10.3168/jds.2019-17713) as detailed below from wk 15 [NBCS: $\mathrm{BCS}=3.05 \pm 0.19$ and backfat thickness $(\mathbf{B F T})=0.87 \pm 0.27$, means \pm $\mathrm{SD}$; HBCS: $\mathrm{BCS}=3.44 \pm 0.24$ and $\mathrm{BFT}=1.36 \pm 0.39]$ to wk 7 before the anticipated calving date to reach divergent BCS and BFT at dry-off [NBCS: BCS $<3.5$ $(3.02 \pm 0.24)$ and BFT $<1.2 \mathrm{~cm}(0.92 \pm 0.21)$; means \pm SD; HBCS: BCS $>3.75(3.82 \pm 0.33)$ and BFT $>1.4$ $\mathrm{cm}(2.36 \pm 0.35)]$. The 2 groups were initially selected from the entire herd (150 cows) by their history of BCS and BFT records from the year preceding the trial to find cows divergent in both variables to have 2 groups with equal numbers. The preselected cows were also stratified for comparable milk yields (NBCS: 10,361 kg $\pm 302 \mathrm{~kg}$; HBCS: $10,315 \pm 437 \mathrm{~kg}$, means \pm SD). From wk 15 to 7 before anticipated calving date, NBCS cows were fed a low-energy ration $\left(\mathrm{NE}_{\mathrm{L}} 6.8 \mathrm{MJ} / \mathrm{kg}\right.$ of $\left.\mathrm{DM}\right)$, and HBCS cows were fed a high-energy ration (7.2 MJ/ $\mathrm{kg}$ of DM). All diets were fed as TMR consisting of $63 \%$ roughage and $37 \%$ concentrate in the high-energy diet and $74 \%$ roughage and $26 \%$ concentrate in the low-energy diet. The diets were balanced to meet or exceed the nutritional requirements of Holstein cows according to the recommendation of the Society of Nutrition Physiology in Germany (GfE, 2001). One person monitored both BCS and BFT every 2 wk during the entire period of the trial [15 wk antepartum (ap) to 12 wk pp]. The BCS was estimated on a 5 -point scale $(1=$ emaciated and $5=$ extremely fat) with 0.25 increments (Edmonson et al., 1989), and BFT was assessed in the sacral region using ultrasonography (Agroscan L, ALR 500, 5-MHz linear-array transducer, Echo Control Medical, Angoulême, France). Individual daily feed intake was recorded and the calculations for $\mathrm{NE}_{\mathrm{M}}$, pregnancy, and those for lactation $\left(\mathrm{NE}_{\mathrm{L}}\right)$, as well as milk energy concentrations were made according to the guidelines of the GfE (2001) as follows: 
Net energy balance $\left(\mathbf{E B}, \mathrm{MJ}\right.$ of $\left.\mathrm{NE}_{\mathrm{L}} / \mathrm{d}\right)=$ energy intake (MJ of $\left.\mathrm{NE}_{\mathrm{L}} / \mathrm{d}\right)-\mathrm{NE}_{\mathrm{M}}\left(\mathrm{MJ}\right.$ of $\mathrm{NE}_{\mathrm{L}} / \mathrm{d}$ )

$-\mathrm{NE}_{\mathrm{L}}\left(\mathrm{MJ}\right.$ of $\left.\mathrm{NE}_{\mathrm{L}} / \mathrm{d}\right)$;

$\mathrm{NE}_{\mathrm{M}}\left(\mathrm{MJ}\right.$ of $\left.\mathrm{NE}_{\mathrm{L}} / \mathrm{d}\right)=0.293 \times \mathrm{BW}^{0.75} ;$

Maintenance and pregnancy (6 to 4 wk ap;

$$
\left.\mathrm{MJ} \text { of } \mathrm{NE}_{\mathrm{L}} / \mathrm{d}\right): \mathrm{NE}_{\mathrm{M}}+13 \text {; }
$$

Maintenance and pregnancy (3 wk ap until calving;

$$
\left.\mathrm{MJ} \text { of } \mathrm{NE}_{\mathrm{L}} / \mathrm{d}\right): \mathrm{NE}_{\mathrm{M}}+18 \text {; }
$$

Milk energy concentration ( $\mathrm{MJ}$ of $\mathrm{NE}_{\mathrm{L}} / \mathrm{kg}$ ) $=$

$$
\begin{aligned}
& 0.38 \times \text { milk fat }(\%)+0.21 \\
& \times \text { milk protein }(\%)+0.95 ;
\end{aligned}
$$

Energy requirement for lactation $\mathrm{NE}_{\mathrm{L}}$

$\left(\mathrm{MJ}\right.$ of $\left.\mathrm{NE}_{\mathrm{L}} / \mathrm{d}\right)=[$ milk energy concentration

$\left(\mathrm{MJ}\right.$ of $\left.\left.\mathrm{NE}_{\mathrm{L}} / \mathrm{kg}\right)+0.086\right] \times$ milk yield $(\mathrm{kg} / \mathrm{d})$;

Energy intake $=$ daily DMI $\times$ energy content of the TMR $\left(\mathrm{NE}_{\mathrm{L}} / \mathrm{kg}\right.$ of $\left.\mathrm{DM}\right)$.

\section{Blood and Muscle Tissue Sampling}

Blood samples were collected from the median caudal vein before the morning feeding on $\mathrm{d}-49,3,21$, and 84 relative to calving. After clotting and subsequent centrifugation $(10 \mathrm{~min}, 2,000 \times g)$, sera were obtained and stored at $-20^{\circ} \mathrm{C}$ until analysis. Biopsies were collected from the semitendinosus muscle at $\mathrm{d}-49,3,21$, and 84 relative to calving. Biopsies were performed while animals were fixed in a headlock and sedated by intravenous injection with xylazine $(20 \mathrm{mg} / \mathrm{mL}, 0.1 \mathrm{~mL} / 100$ $\mathrm{kg}$ of BW; CP-Pharma Handels GmbH, Burgdorf, Germany). The surgical area was cleaned, shaved, and disinfected with $70 \%$ isopropyl alcohol. Muscle samples were obtained after local anesthesia with procaine hydrochloride $(20 \mathrm{mg} / \mathrm{mL}, 8 \mathrm{~mL}$ per biopsy; Richter Pharma AG, Wels, Austria) by making a 1-cm incision through the skin and underlying soft tissue with a sterile scalpel blade to expose the muscle. Approximately 200 to $300 \mathrm{mg}$ of muscle tissue was collected using a Bard Magnum biopsy instrument and Bard Magnum core tissue biopsy needles (12-gauge $\times 20 \mathrm{~cm}$, C.R . Bard Inc., Tempe, AZ). After tissue excision, oxytetracycline hydrochloride was applied on the skin (25 $\mathrm{mg} / \mathrm{mL}$, Engemycin, MSD Animal Health Innovation GmbH, Schwabenheim an der Selz, Germany) and a ketoprofen injection $(100 \mathrm{mg} / \mathrm{mL}, 3 \mathrm{~mL} / 100 \mathrm{~kg}$ of BW; Streuli Pharma AG, Uznach, Switzerland) was given to prevent infection and for analgesia, respectively. Tissue samples were immediately weighed, frozen in liquid nitrogen, and stored at $-80^{\circ} \mathrm{C}$ until analysis.

\section{Acylcarnitine Profiling}

The AcylCN profiles in serum and skeletal muscle were determined by flow-injection electrospray ionization-tandem mass spectrometry (FI-ESI-MS) profiling through targeted metabolomics using the AbsoluteIDQ p180 kit (Biocrates Life Sciences AG, Innsbruck, Austria). This kit was validated according to European Medicines Agency guidelines (EMEA, 2011), which implies proof of reproducibility within a given error range. For serum, equal volumes $(10 \mu \mathrm{L})$ of the thawed sample were applied directly to the assay. Frozen muscle samples were weighed $(25 \mathrm{mg}$ of tissue per sample), homogenized, and extracted using homogenization tubes with ceramic beads $(1.4 \mathrm{~mm})$ and a Precellys 24 homogenizer with an integrated cooling unit (PEQLab Biotechnology GmbH, Darmstadt, Germany). Three microliters of a dry ice-cooled mixture of ethanol:phosphate buffer (85:15 vol:vol) was added per milligram of frozen muscle tissue. After centrifugation at room temperature for $10 \mathrm{~min}$ at $2,750 \times g, 10 \mu \mathrm{L}$ of the homogenate supernatant was applied to the well plate of the p180 kit. To minimize human error, sample handling was performed using a Hamilton Microlab STAR robot (Hamilton Bonaduz AG, Bonaduz, Switzerland). The drying steps were performed using an Ultravap nitrogen evaporator (Porvair Sciences, Leatherhead, UK), along with standard laboratory equipment. The tissue preparation and assay procedures of the AbsoluteIDQ p180 kit have been described in detail previously (Römisch-Margl et al., 2012; Zukunft et al., 2013, 2018). Mass spectrometric analyses were performed on an API 4000 triple quadrupole system (AB Sciex Deutschland GmbH, Darmstadt, Germany) equipped with a 1200 Series HPLC (Agilent Technologies Deutschland $\mathrm{GmbH}$, Böblingen, Germany) and an HTC PAL auto-sampler (CTC Analytics, Zwingen, Switzerland) controlled by the software Analyst 1.6.1 (AB Sciex Deutschland $\mathrm{GmbH}$ ). Internal standards were used as a reference for the calculation of AcylCN concentrations. Mass detection and compound identification were performed by multiple reaction monitoring. Data evaluation for AcylCN concentrations and quality assessment was performed with the MultiQuant 3.0.1 software (AB Sciex Deutschland $\mathrm{GmbH}$ ) and the MetIDQ software package (Biocrates Life Sciences AG), which is an integral part of the AbsoluteIDQ p180 kit. The serum concentrations are given in micromoles per 
(a)

\begin{tabular}{|cc|}
\hline Late lactation & \\
\cline { 2 - 2 } Group NBCS & $\begin{array}{c}\text { Dryin } \\
\text { (Energy-reduced ration) } \\
6.8 \mathrm{NEL} \text { MJ/kg DM }\end{array}$ \\
\hline Group HBCS & $\begin{array}{c}\text { (High-energy ration) } \\
7.2 \mathrm{NEL} \text { MJ/kg DM }\end{array}$ \\
\hline
\end{tabular}

NBCS

Blood and muscle sampling $\Rightarrow$

HBCS
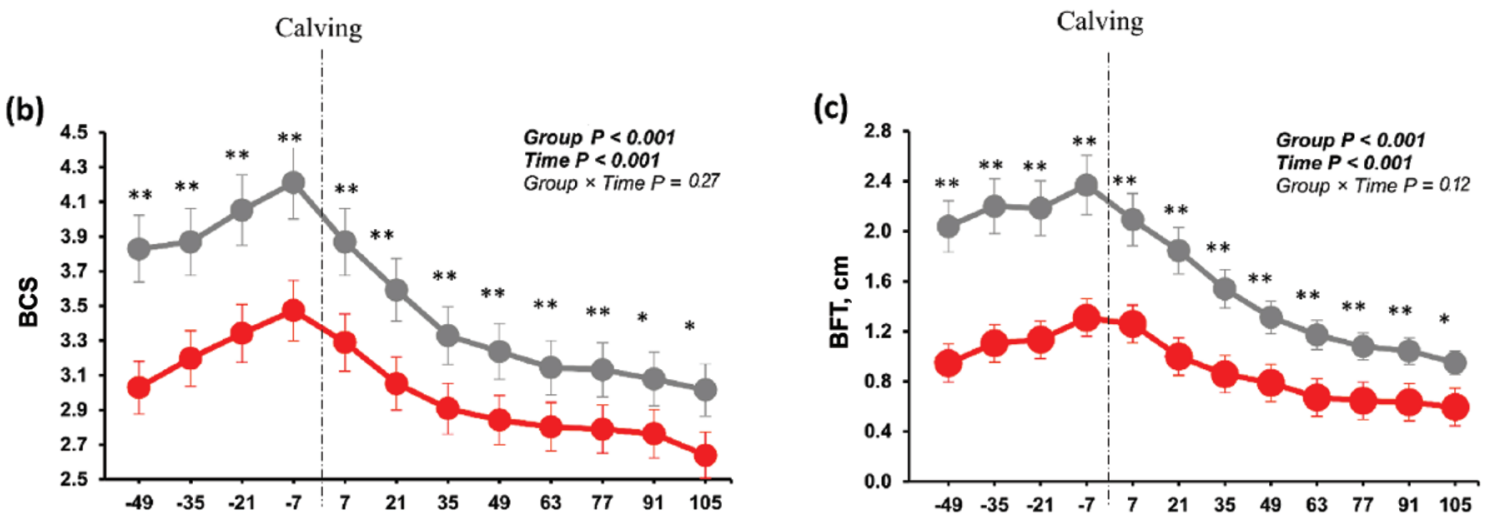

(d)

(e)
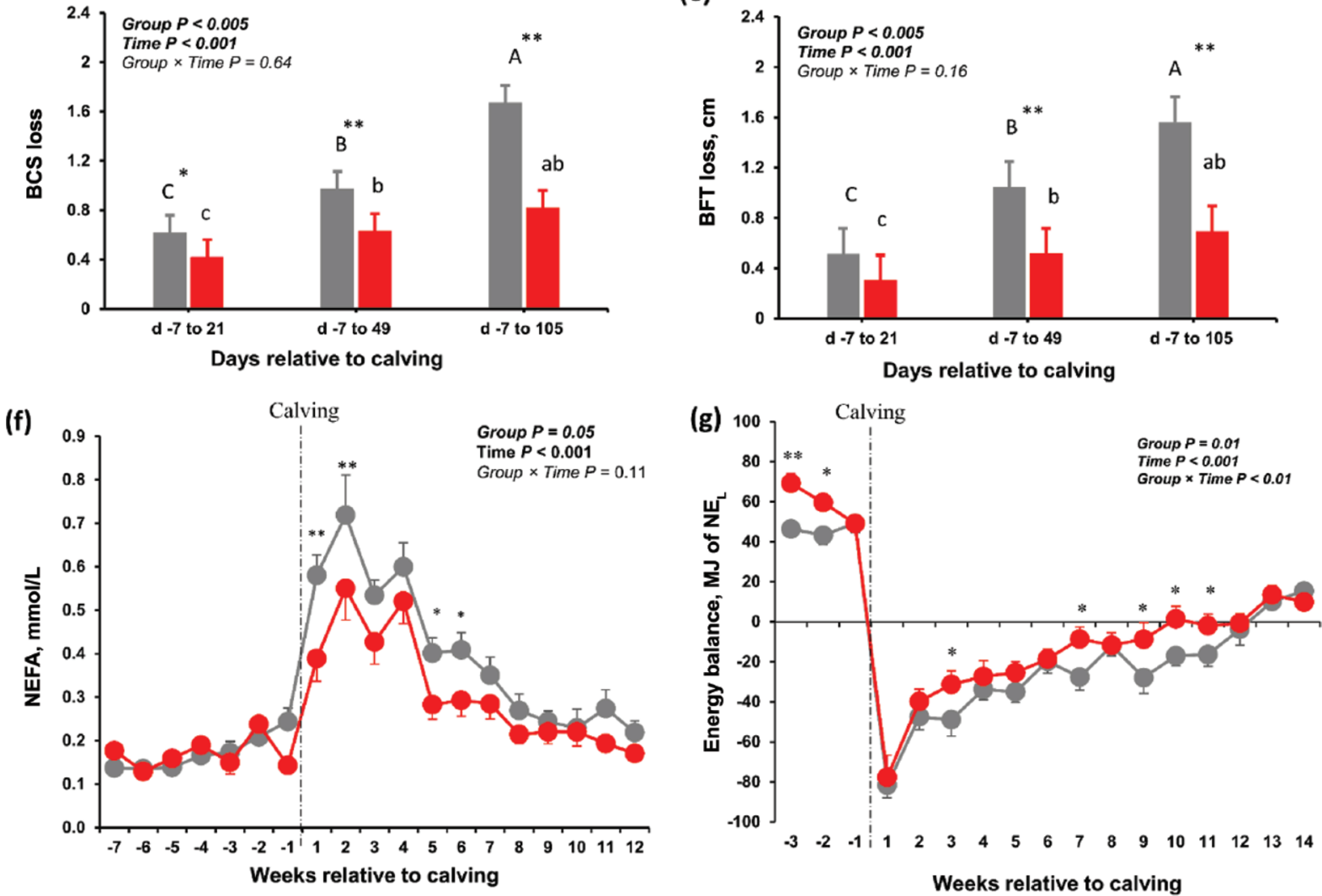

Figure 1. Design of the animal experiment in the present study (a); BCS (b); back fat thickness (BFT; c); BCS loss (d) and BFT (e) loss of normal-conditioned (NBCS; $<3.5$ BCS or $<1.2 \mathrm{~cm} \mathrm{BFT)} \mathrm{and} \mathrm{over-conditioned} \mathrm{(HBCS;}>3.75$ BCS or $>1.4 \mathrm{~cm}$ BFT) cows during the experimental period ( $\mathrm{n}=19$ per group); serum nonesterified fatty acids (NEFA) concentration (f) and energy balance ( $\mathrm{g}$ ) in HBCS and NBCS cows during late gestation and early lactation. Symbols indicate differences $\left({ }^{*} P<0.05 ;{ }^{*} P<0.01\right)$ between the groups at a given time. Different uppercase letters $(\mathrm{A}-\mathrm{C})$ indicate differences between time points within HBCS cows, and different lowercase letters (a-c) indicate differences between time points within NBCS cows. Data for BCS, BFT, serum NEFA, BCS loss, BFT loss, and energy balance, as presented means \pm SE, are from Schuh et al. (2019). 
liter and muscle concentrations are in picomoles per milligram of tissue.

\section{RNA Extraction and Quantitative Real-Time Reverse Transcription-PCR}

Total RNA was extracted from muscle homogenates using Qiagen reagent (Qiagen, Hilden, Germany) according to the manufacturer's protocol. The extracted RNA was purified using the RNeasy Mini Kit (Qiagen) including the On-Column DNase I treatment to remove residual genomic DNA from the RNA samples. The quantity and purity of RNA were evaluated by measuring absorbance at 260 and $280 \mathrm{~nm}$ using a Nanodrop 1000 spectrophotometer (PEQLab Biotechnology $\mathrm{GmbH}$ ). The RNA integrity was assessed using ethidium bromide-denaturing RNA electrophoresis and rechecked in randomly selected samples using an Agilent 2100 Bioanalyzer (Agilent Technologies, Waldbronn, Germany) with the RNA 6000 Nano Kit system according to the manufacturer's protocol to determine RNA integrity number $(7.63 \pm 0.17$; mean \pm SD). Only samples with a $28 \mathrm{~S}: 18 \mathrm{~S}$ ratio $\geq 2.0$ and RNA integrity number $\geq 7.0$ were used for downstream applications. Reverse transcription was conducted with $250 \mathrm{ng}$ of total RNA per $20-\mu \mathrm{L}$ reaction using RevertAid reverse transcriptase $(200 \mathrm{U} / \mu \mathrm{L}$; Thermo Fisher Scientific, Dreireich, Germany), 20 U of RiboLock ribonuclease inhibitor (Fermentas, St. Leon-Rot, Germany), and 500 $\mu M$ dNTPs, with 200 pmol of random hexamer primers (Sigma-Aldrich, Nümbrecht, Germany) for $10 \mathrm{~min}$ at $27^{\circ} \mathrm{C}, 60 \mathrm{~min}$ at $42^{\circ} \mathrm{C}$, and $1 \mathrm{~min}$ at $99^{\circ} \mathrm{C}$. For each run, a no-reverse-transcriptase (-RT) control and notemplate control (NTC) were included. Reverse transcription was performed in duplicate for each sample. Analyses by quantitative real-time PCR (qPCR) were performed using an Mx3000P PCR cycler (Stratagene, Amsterdam, the Netherlands; Agilent, Santa Clara, CA) following the Minimum Information for Publication of qPCR Experiments (MIQE) guidelines (Bustin et al., 2009). The qPCR conditions and the characteristics of the primers are presented in Table 1. The reaction was performed in triplicate in a total volume of $10 \mu \mathrm{L}$ composed of $2 \mu \mathrm{L}$ of cDNA (diluted 1:4) as a template, $1 \mu \mathrm{L}$ of the assay-specific primer mix, $5 \mu \mathrm{L}$ of the SYBR Green JumpStart Taq Readymix (SigmaAldrich Chemie GmbH, Steinheim, Germany), and 2 $\mu \mathrm{L}$ of water. An NTC for quantitative PCR, as well as an NTC and -RT for cDNA, were included in each run. For each PCR reaction, a standard curve using a serial dilution of cDNA was generated to calculate efficiency-corrected relative quantities of the targets (run-specific target amplification efficiency). To determine the most stably expressed genes across groups for subsequent data normalization, a set of 5 genes (Saremi et al., 2012) was tested, and their stability was evaluated using qBASE ${ }^{\mathrm{PLUS}}$ (version 2.0; Biogazelle, Ghent, Belgium). Three reference genes including low-density lipoprotein receptor-related protein 10 (LRP10), RNA polymerase II (POLR2A), and emerin $(E M D)$ were determined as the most stable reference genes. All subsequent calculations and data quality controls were performed using qBASE ${ }^{\text {PLUS }}$ software (Hellemans et al., 2007). The output data from the software were calibrated normalized relative quantities (CNRQ) values.

\section{Data Analysis and Statistics}

A repeated-measures model was fitted to data (both serum and muscle) using the PROC MIXED procedure of SAS (version 9.4; SAS Institute Inc., Cary, NC). A covariance structure was chosen based on the best Akaike information criterion (AIC) and Bayesian information criterion (BIC) indices. The model consisted of group, time, and interaction of group and time as fixed effects, and cow as a random effect. In the preliminary data analysis, parity was included in the model as fixed effect, as well as group, time, and interaction of group and time. The outcome of this preliminary statistical evaluation did not show any significant effect of parity on the tested variables in this study. Therefore, parity was disregarded as an effect in the model for the final statistical analysis of the data. Before analysis, all data were tested for normality of distribution by evaluating the Shapiro-Wilk statistic using the UNIVARIATE procedure of SAS; where appropriate, they were transformed using a $\log _{10}$ transformation. The results of the mRNA abundance calculated by $\mathrm{qBASE}^{\mathrm{PLUS}}$ (i.e., CNRQ values) were used for statistical analysis of the mRNA data. The Tukey-Kramer adjustment was applied to account for multiple comparisons. The threshold of significance was set at $P \leq 0.05$, and trends were declared at $0.05<P \leq 0.10$. Furthermore, principal component analysis (PCA, an unsupervised method), orthogonal partial least squares discriminant analysis (OPLS-DA), and OPLS-DA loading S-plots were conducted on the serum data to identify those AcylCN showing significant differences between groups using MetaboAnalyst 4.0 (Chong et al., 2018). The robustness of the OPLS-DA models was evaluated based on crossvalidation, as described by Szymańska et al. (2012). For the serum data, missing values were imputed using the $k$-nearest-neighbor algorithm, and AcylCN with more than $50 \%$ of missing values (i.e., values below the limit of detection) were removed. The serum data were generalized log-transformed and auto-scaled to correct for heteroscedasticity and to minimize mask effects and data skewness (van den Berg et al., 2006). 
Table 1. Characteristics of primers and real-time PCR conditions

\begin{tabular}{|c|c|c|c|c|c|}
\hline Gene $^{1}$ & Sequence $\left(5^{\prime}-3^{\prime}\right)$ & $\begin{array}{l}\text { NCBI } \\
\text { Accession no. }\end{array}$ & $\begin{array}{l}\text { Length } \\
\text { (bp) }\end{array}$ & $\begin{array}{c}\text { Mean } \\
\mathrm{Cq}^{2}\end{array}$ & $\begin{array}{l}\text { Annealing condition } \\
\qquad(\mathrm{s} / \circ \mathrm{C})^{3}\end{array}$ \\
\hline \multicolumn{6}{|l|}{ CPT1b } \\
\hline Forward & GCAGATGATGGCTATGGA & NM 001034349.2 & 78 & 30.66 & $20 / 61$ \\
\hline \multicolumn{6}{|c|}{ 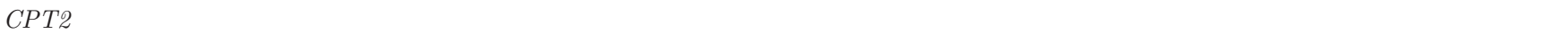 } \\
\hline Forward & GTAGCCAGTAAGCACTATTC & \multirow[t]{2}{*}{ NM 001045889.2} & \multirow[t]{2}{*}{180} & \multirow[t]{2}{*}{27.55} & \multirow[t]{2}{*}{$60 / 59$} \\
\hline Reverse & CCAAGTCTTACCTCCTGATA & & & & \\
\hline Reverse & ATAGGGTTGCTGTCCCTGTG & BC149232 & 139 & 25.22 & $30 / 61$ \\
\hline \multicolumn{6}{|l|}{ POLR2A } \\
\hline Forward & GAAGGGGGAGAGACAAACTG & \multirow[t]{2}{*}{ X63564 } & \multirow[t]{2}{*}{86} & \multirow[t]{2}{*}{25.28} & \multirow[t]{2}{*}{$60 / 60$} \\
\hline Reverse & GGGAGGAAGAAGAAAAAGGG & & & & \\
\hline \multicolumn{6}{|c|}{ ber } \\
\hline Forward & CCAGGCCCACCAAGAAGAA & \multirow[t]{2}{*}{ NM_001034489 } & \multirow[t]{2}{*}{125} & \multirow[t]{2}{*}{26.43} & \multirow[t]{2}{*}{$45 / 59$} \\
\hline Reverse & TTATACCTTCCAGGAGGTCCATGT & & & & \\
\hline
\end{tabular}

${ }^{1} C P T 1 b=$ carnitine palmitoyltransferase 1, muscle isoform; $C P T 2=$ carnitine palmitoyltransferase $2 ; L R P 10=$ lipoprotein receptor-related protein $10 ; E I F 3 K=$ eukaryotic translation initiation factor $3, P O L R 2 A=$ RNA polymerase II; $E M D=$ emerin.

${ }^{2}$ Mean quantification cycle.

${ }^{3}$ Initial denaturation for $10 \mathrm{~min}$ at $90^{\circ} \mathrm{C}$; denaturation for $30 \mathrm{~s}$ at $95^{\circ} \mathrm{C}$; extension for $30 \mathrm{~s}$ at $72^{\circ} \mathrm{C}$, except for $L R P 10\left(20 \mathrm{~s}\right.$ at $\left.72^{\circ} \mathrm{C}\right)$.

\section{RESULTS}

\section{Animal Grouping}

The grouping according to BCS and BFT at 15 wk ap yielded initial differences of about $0.4 \mathrm{BCS}$ points and $0.5 \mathrm{~cm}$ in BFT. Feeding rations with different energy levels from 15 wk ap until dry-off augmented the differences to $0.8 \mathrm{BCS}$ units and $1.0 \mathrm{~cm}$ of BFT in wk 7 ap (Figure 1b,c). More precisely, the BCS of cows in both groups declined during lactation but the losses were greater in HBCS than in NBCS cows (Figure 1d, e). The serum concentrations of nonesterified fatty acids (NEFA) were elevated in both groups from $\mathrm{d}-49$ to 21 and decreased thereafter, but they were greater $(\mathrm{d} 3$ and $21, P<0.001$ ) in HBCS than in NBCS (Figure 1f). A group $\times$ time interaction $(P<0.01)$ was observed for the calculated EB (Figure 1g). The calculated EB was more negative in HBCS cows than in NBCS cows in wk 3 and 2 ap, as well as in wk 3, 7, 9, 10, and 11 pp.

\section{Clinical Health Events}

In the current study, several animals were too small to allow for valid comparisons of disease incidence. A group of 40 dairy cows without a previous history of disease, including mastitis (with a confirmed pregnancy test), were enrolled in the study. Results from the 2 cows (1 cow from each group) that failed to complete the sampling schedule were excluded. No clinical health events occurred before calving. A summary of clinical health events during the first 6 wk of lactation are presented in Supplemental Table S2 (https://doi.org/10 $.3168 /$ jds.2019-17713). Mastitis was the most common clinical ailment. Numerical differences existed between HBCS and NBCS cows in the number of cows affected by clinical events (ketosis and milk fever).

\section{Serum AcyICN Profiles}

A group $\times$ time interaction $(P<0.01)$ was observed for concentrations of free carnitine and acetylcarnitine in the serum (Figure 2). In HBCS, the serum concentrations of free carnitine were greater ap compared with pp values. In NBCS, serum carnitine decreased from d -49 to $\mathrm{d} 21$ and remained unchanged thereafter. Serum acetylcarnitine concentrations were higher in HBCS than in NBCS cows at $\mathrm{d} 3$ and $21 \mathrm{pp}(P<0.001$, Figure 2). The serum concentrations of some shortchain [propionylcarnitine (C3), butyrylcarnitine (C4), butenylcarnitine (C4:1), and valerylcarnitine (C5)], medium-chain [octanoylcarnitine $(\mathrm{C} 8)$, nonaylcarnitine (C10), and decadienylcarnitine (C10:2)], and long-chain AcylCN [hexadecanoylcarnitine (C16), hexadecadienylcarnitine (C16:2), and octadecadienylcarnitine (C18:2)] were not different between the groups (Figures 2 and $3)$. Both groups had reduced C4 and C5 concentrations during the pp period $(P<0.01$, Figure 2$)$. A significant group $\times$ time interaction was observed for serum concentrations of hexanoylcarnitine (C6), dodecanoylcarnitine $(\mathrm{C} 12)$, and tetradecenoylcarnitine 
(C14:1; Figures 2 and 3). The serum concentrations of C6, C12, and C14:1 were lower in HBCS than in NBCS cows on $\mathrm{d}-49(P<0.01)$. The serum concentrations of tetradecanoylcarnitine (C14; d 3, 21, 84), C16 (d 21), octadecanoylcarnitine (C18; d 3, 21), and octadecenoylcarnitine $(\mathrm{C} 18: 1 ; \mathrm{d} 3,21)$ were higher $(P<0.01)$ in HBCS than in NBCS cows during early lactation (Figure 3).

The score plots of PCA of serum AcylCN are presented in Figure 4a, d. With supervised (OPLS-DA) pattern recognition analyses in the serum on $\mathrm{d} 21$, both groups were clearly discriminated from each other (Figure $4 \mathrm{~b}, \mathrm{e})$ by the orthogonal component $(\mathrm{t}[1])$ based on the model with an $\mathrm{R}^{2} \mathrm{Y}$ value of $0.842(P<0.01)$, indicating the goodness of fit of the data, and with $\mathrm{Q}^{2}$ coefficient values of $0.262(P=0.02)$, estimating the predictive ability of the model (Figure $4 \mathrm{~g}, \mathrm{~h}$ ). The S-plots of $\mathrm{p}(1)$ and $\mathrm{p}(\mathrm{corr})(1)$ were generated using auto-scaling to identify those serum AcylCN contributing to the discrimination between groups (Figure 4c, f). The S-plots showed that the AcylCN with lower or higher $\mathrm{p}$ (corr) values were the more relevant AcylCN to explain the discrimination between HBCS and NBCS cows. On d 21, the levels of AcylCN with positive $\mathrm{p}($ corr $)$ values [hydroxypropionylcarnitine $(\mathrm{C} 3-\mathrm{OH}), \quad$ hydroxytetradecadienylcarnitine (C14:2 $-\mathrm{OH})$, and propenoylcarnitine (C3:1)] were decreased by over-conditioning around calving, whereas AcylCN with negative values [acetylcarnitine, hydroxyhexadecenoylcarnitine (C16:1-OH), C16, C18, and $\mathrm{C} 18: 1]$ were increased. In the S-plot of serum on d 84, we detected decreased levels of hydroxybutyrylcarnitine (C3-DC), hydroxyvalerylcarnitine (C5-OH), C5, and $\mathrm{C} 10: 2$, whereas those of acetylcarnitine, C6, C14, and C16 were increased (Figure 4f).

\section{AcyICN Profiles in Skeletal Muscle}

The muscle concentrations of most short-chain [free carnitine, acetylcarnitine, C3, C3-DC, C3-OH, C3:1, C4, C4:1, glutarylcarnitine (C5-DC), methylglutarylcarnitine (C5-M-DC), tiglylcarnitine (C5:1), C6, hexenoylcarnitine (C6:1), pimelylcarnitine (C7-DC), C8], medium-chain [C10, decanoylcarnitine (C10:1), C10:2, C12, dodecanedioylcarnitine (C12-DC), dodecenoylcarnitine (C12:1), C14, C14:1], and long-chain [C16, hydroxyhexadecanoylcarnitine $(\mathrm{C} 16-\mathrm{OH})$, hexadecenoylcarnitine (C16:1), C16:1-OH, C16:2, hydroxyhexadecadienylcarnitine (C16:2-OH), C18, and C18:1 $-\mathrm{OH})$ AcylCN were not different between the groups (Figure 5). A significant group $\times$ time interaction was observed for muscle concentrations of C5 $(P=0.03)$ with a higher value for HBCS than NBCS cows on $\mathrm{d}$ 84 pp. The muscle concentrations of $C_{-}(P=0.03)$,
C18:1- (tendency $P=0.08)$, and C18:2- $(P=0.01)$ AcylCN were lower, whereas those of C14:2-AcylCN $(P=0.001)$ were higher in HBCS than in NBCS cows (Figure 5). In both groups, muscle concentrations of acetylcarnitine, C7-DC, and some long-chain AcylCN (C16:1-OH, C18:0, and C18:1) were increased $(P<$ $0.05)$ during the pp period (Figure 5$)$. The muscle concentrations of C18:2-AcylCN were elevated $(P<0.05)$ from d 21 to 84 in both groups (Figure 5).

\section{CPT1 and CPT2 Ratios}

The serum CPT1 ratio, the ratio of free carnitine to the sum of palmitoylcarnitine and stearoylcarnitine [carnitine $/(\mathrm{C} 16: 1+\mathrm{C} 18: 0)]$ was lower $(P<0.01)$ on d -49 but tended $(P=0.08)$ to be higher in NBCS compared with HBCS cows on d 21 (Figure 6a). The serum CPT1 ratio decreased with the onset of lactation $(P<0.001$, Figure $6 \mathrm{a})$. The serum $\mathrm{CPT} 2$ ratio $[(\mathrm{C} 16: 0+\mathrm{C} 18: 1) / \mathrm{C} 2]$ did not differ between groups and increased with the onset of lactation in both groups $(P$ $<0.001$, Figure $6 \mathrm{~b})$. The muscle CPT1 ratio was higher in HBCS than in NBCS cows on d 21 and tended $(P$ $=0.08)$ to decrease after parturition (Figure 6c). The muscle CPT2 ratio did not differ between the groups or time points (Figure 6d).

\section{mRNA Abundance of CPT in Skeletal Muscle}

No differences in mRNA abundance of $C P T 1 b$ and CPT2 in skeletal muscle were observed between the groups (Figure 7). The mRNA abundance of $C P T 1 b$ increased from $\mathrm{d}-49$ to $3(P<0.001)$, followed by a decline to nearly ap values by d 21 and 84 in both groups. The mRNA abundance of CPT2 increased from d -49 to $21(P<0.01)$, followed by a decline to nearly ap values by $\mathrm{d} 84$ in both groups (Figure 7 ).

\section{DISCUSSION}

Major metabolic alterations involving lipid metabolism typically occur in dairy cows during the transition from late gestation to lactation (Weber et al., 2016). To gain insight into the relationship of body condition at parturition and FAO, we profiled AcylCN in the serum and skeletal muscle of periparturient dairy cows. Cows were fed differently from wk 15 to 7 ap to reach the targeted BCS and BFT until dry-off at $-49 \mathrm{~d}$ before calving. Thus, it is likely that the observed responses in this experiment on $\mathrm{d}-49$ might have been affected by differential feeding during late lactation. Acylcarnitines are utilized by multiple tissues (i.e., liver, skeletal muscle, heart) through tightly controlled mechanisms (Simcox et al., 2017). In the current study, the more 
HBCS NBCS

Free carnitine (C0)

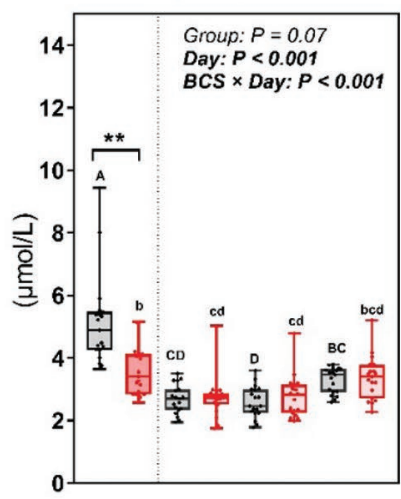

Butenylcarnitine (C4:1)

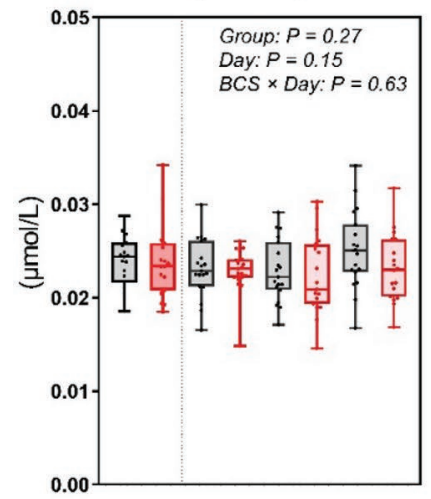

Decanoylcarnitine (C10)

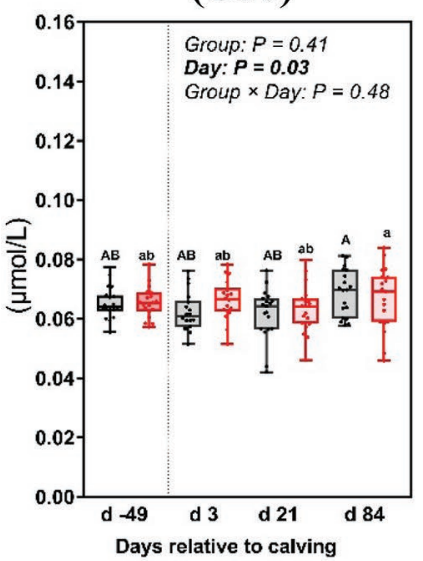

Acetylcarnitine (C2)

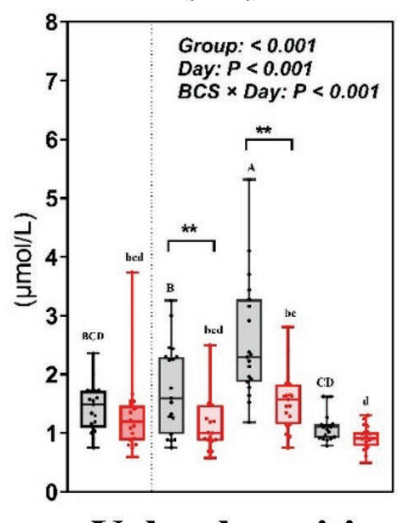

Valerylcarnitine

(C5)

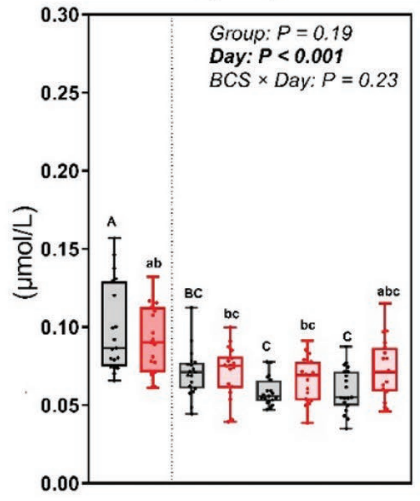

Decadienylcarnitine

(C10:2)

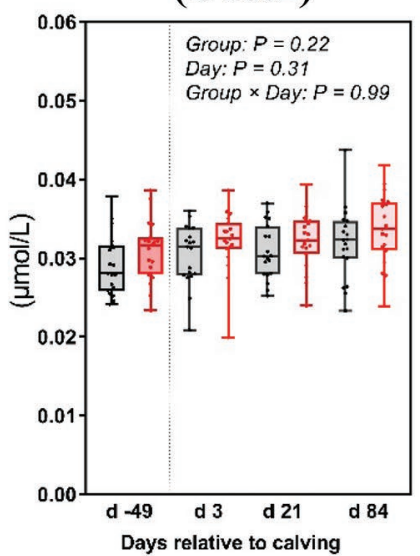

Propionylcarnitine (C3)

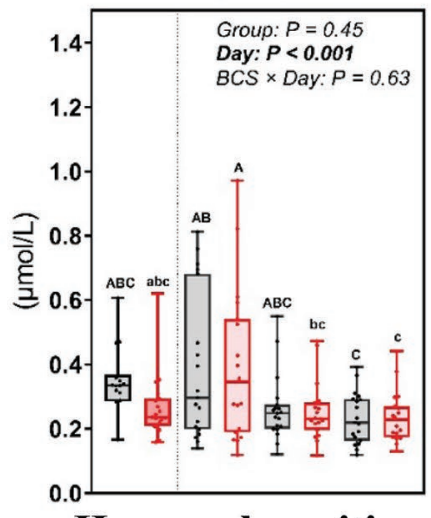

Hexanoylcarnitine

(C6)

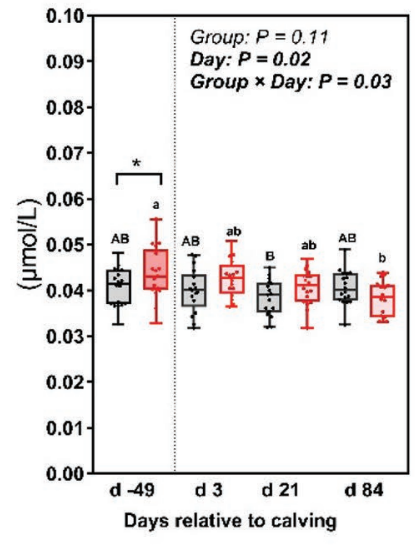

Butyrylcarnitine (C4)

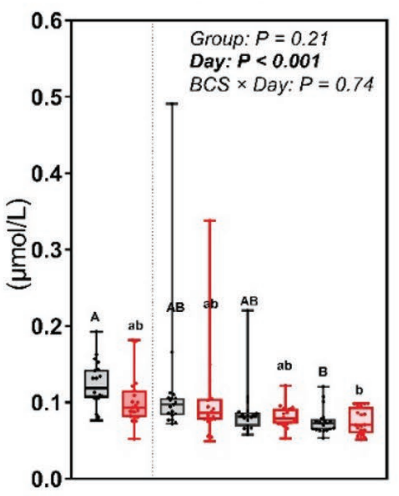

Octanoylcarnitine (C8)

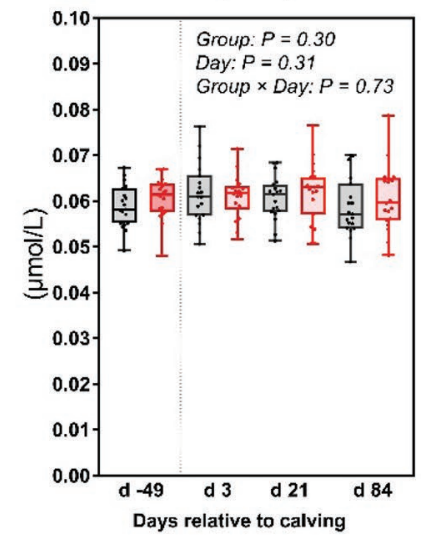

Figure 2. Short- and medium-chain acylcarnitine (C2 to C12) concentrations in serum of normal-conditioned (NBCS; $<3.5$ BCS or $<1.2$ cm $\mathrm{BFT}$ ) and over-conditioned (HBCS; $>3.75 \mathrm{BCS}$ or $>1.4 \mathrm{~cm}$ BFT) cows during the experimental period ( $\mathrm{n}=19$ per group). Symbols indicate differences $\left({ }^{*} P<0.05 ;{ }^{*} P<0.01\right)$ between the groups at a given time. Different uppercase letters (A-C) indicate differences between time points within HBCS cows, and different lowercase letters $(\mathrm{a}-\mathrm{c})$ indicate differences between time points within NBCS cows. In each box plot, the thick horizontal line crossing the box is the median, the bottom and top of the box are the lower and upper quartiles, and the whiskers follow the Tukey boxplot definition. 
HBCS $\square$ NBCS

\section{Dodecanoylcarnitine}

(C12)

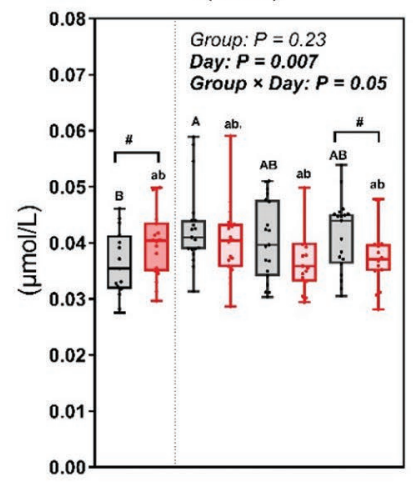

Hexadecanoylcarnitine

(C16)

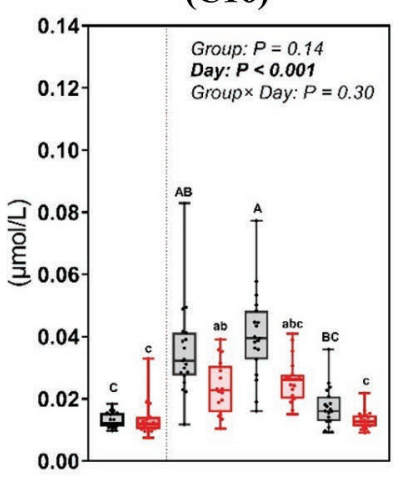

Octadecenoylcarnitine (C18:1)

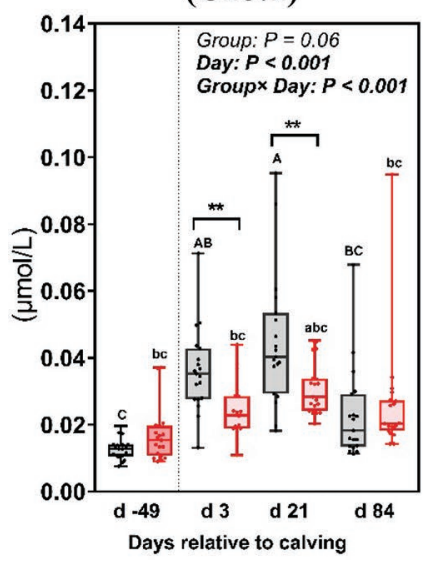

Tetradecanoylcarnitine (C14)

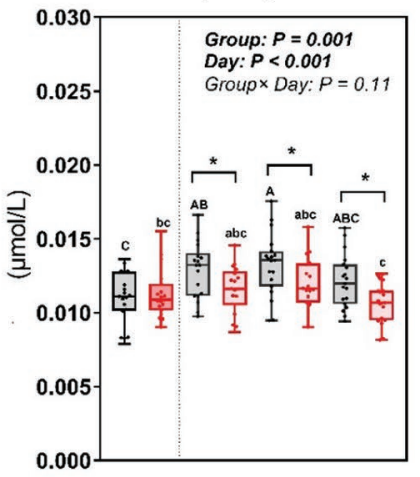

Hexadecadienylcarnitine (C16:2)

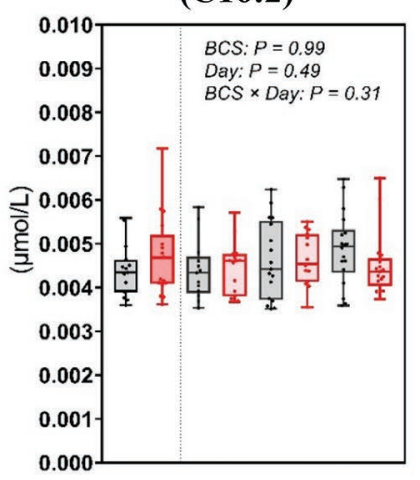

Octadecadienylcarnitine (C18:2)

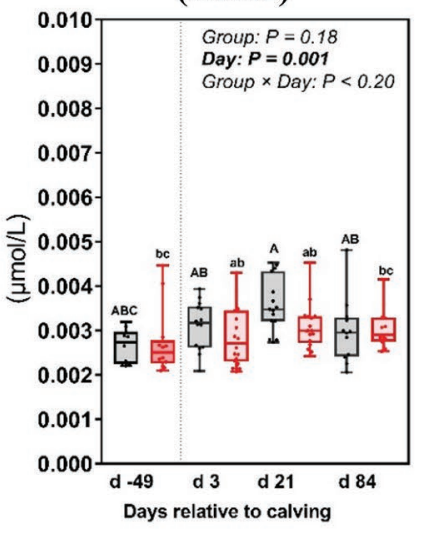

\section{Tetradecenoylcarnitine}

(C14:1)

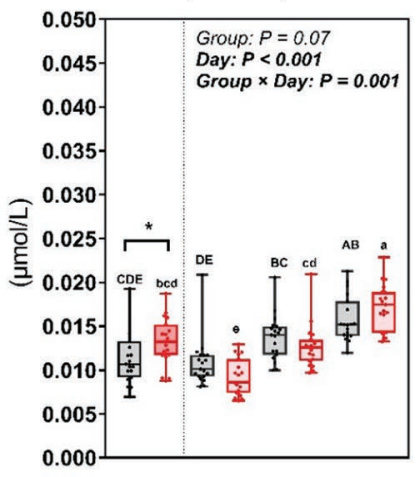

Octadecanoylcarnitine (C18)

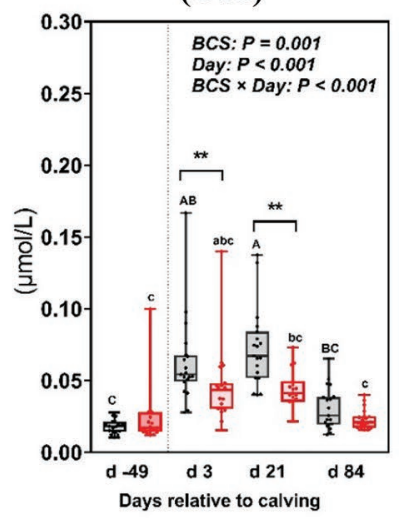

Figure 3. Long-chain acylcarnitine (C12 to C18:2) concentrations in the serum of normal-conditioned (NBCS; $<3.5 \mathrm{BCS}$ or $<1.2 \mathrm{~cm}$ BFT) and over-conditioned (HBCS; $>3.75$ BCS or $>1.4 \mathrm{~cm}$ BFT) cows during the experimental period $(\mathrm{n}=19$ per group). Symbols indicate differences $\left({ }^{*} P<0.05 ;{ }^{*} P<0.01\right)$ between the groups at a given time. Different uppercase letters $(\mathrm{A}-\mathrm{C})$ indicate differences between time points within HBCS cows, and different lowercase letters $(\mathrm{a}-\mathrm{c})$ indicate differences between time points within NBCS cows. In each box plot, the heavy horizontal line crossing the box is the median, the bottom and top of the box are the lower and upper quartiles, and the whiskers follow the Tukey boxplot definition. 
negative EB in HBCS than in NBCS cows was attributable to lower feed intake than milk yield because neither milk nor ECM yield differed between the groups
(Schuh et al., 2019). The most distinct differences in the AcylCN levels between HBCS and NBCS cows were observed in serum. Because of greater lipolysis in early

PCA

OPLS-DA

SPlots
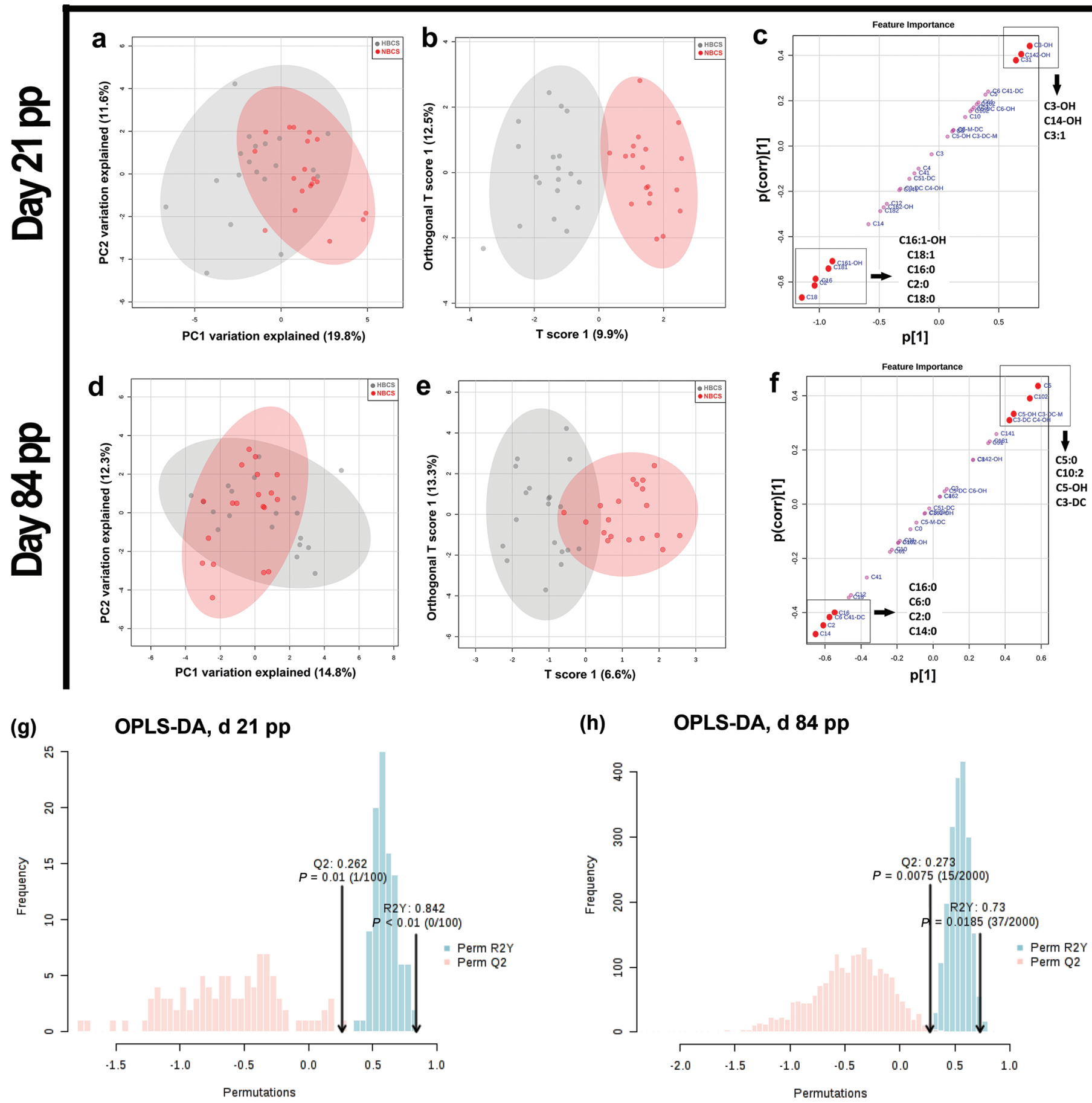

(h) OPLS-DA, d $84 \mathrm{pp}$

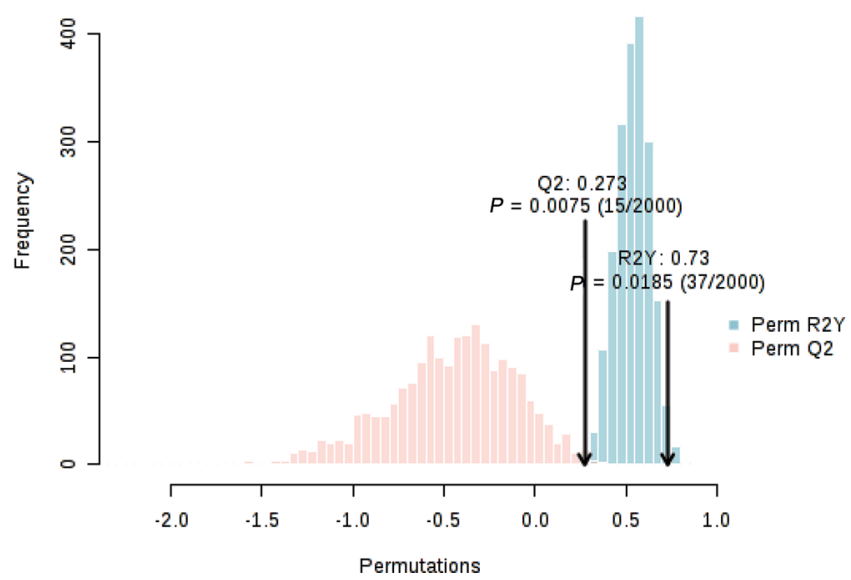

Figure 4. Principal component analysis (PCA; a, d), orthogonal partial least squares-discriminant analysis (OPLS-DA; b, e), and S-plot analyses (c, f) of serum acylcarnitines in normal-conditioned (NBCS; $<3.5$ BCS or $<1.2 \mathrm{~cm}$ BFT) and over-conditioned (HBCS; $>3.75$ BCS or $>1.4 \mathrm{~cm}$ BFT) cows on d 21 and 84 after parturition (pp). S-plots show the variable importance in an OPLS-DA model. Panels g and h show the results of the permutation (Perm) tests for the OPLS-DA models, showing the cross-validated $R^{2} Y$ and $Q^{2}$ coefficients. 
lactation, especially in HBCS cows, mitochondria were assumed to be overloaded with long-chain fatty acyl$\mathrm{CoA}$ and FAO was unable to keep pace, which led to an increase in levels of long-chain AcylCN.
Skeletal muscle is the main reservoir of free carnitine but it cannot itself synthesize carnitine (Vaz and Wanders, 2002; Flanagan et al., 2010). In this study, concentrations of free carnitine in muscle were unchanged

\section{HBCS $\square$ NBCS}

(C0)

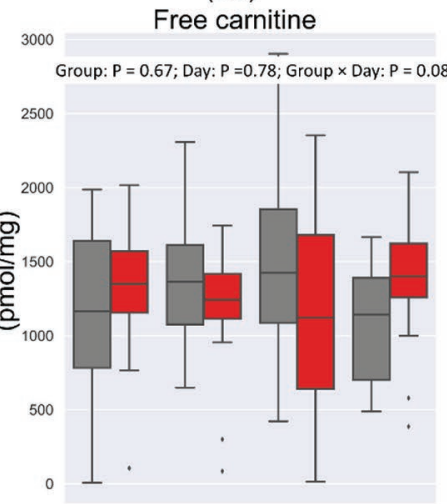

(C3-OH)

Propionylcarnitine

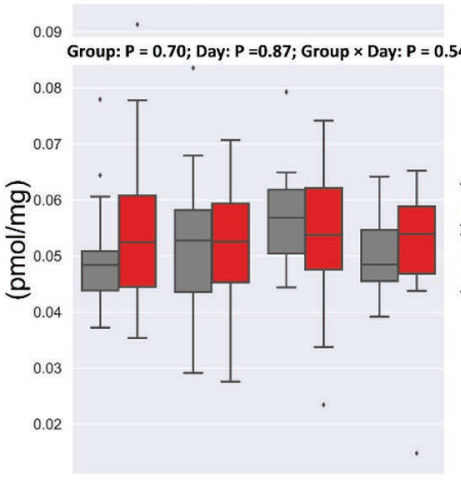

(C6)

Hexanoylcarnitine

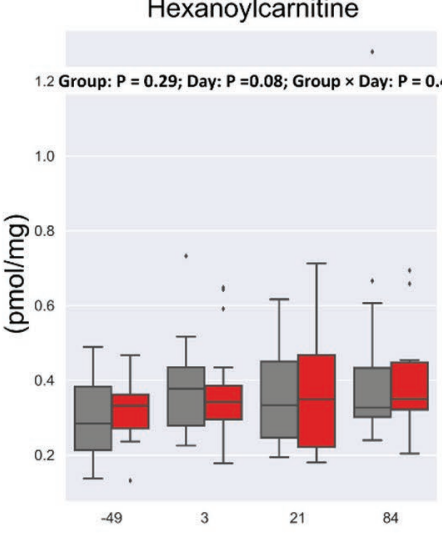

Days relative to calving
(C4)

Butyrylcarnitine
(C2)

Acetylcarnitine
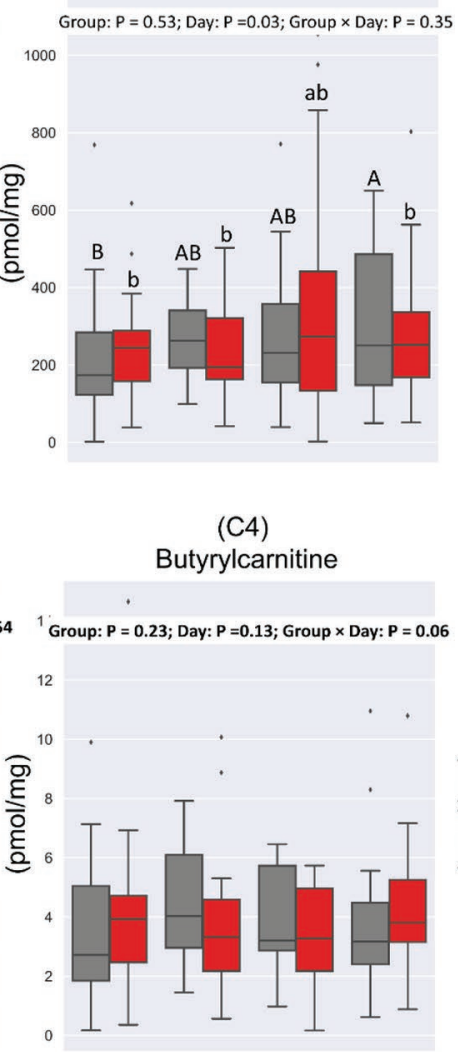

(C7-DC)

Pimelylcarnitine

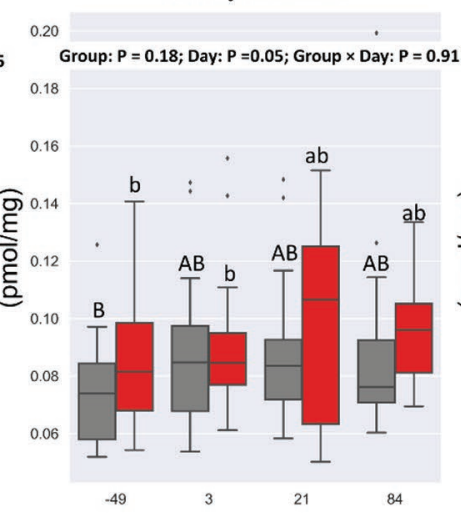

Days relative to calving
(C3)

Propionylcarnitine

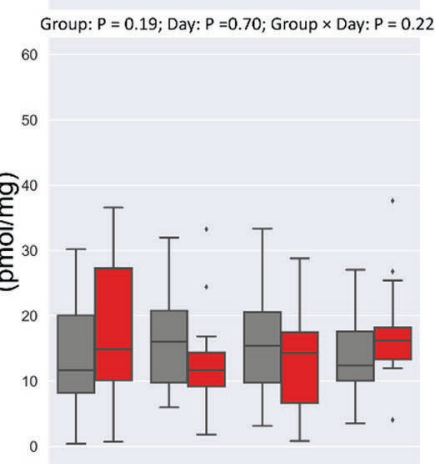

(C5)

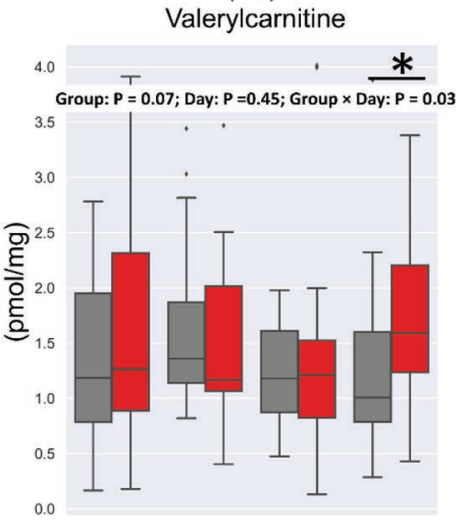

(C8)

Octanoylcarnitine

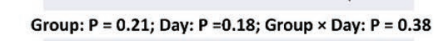

0.6

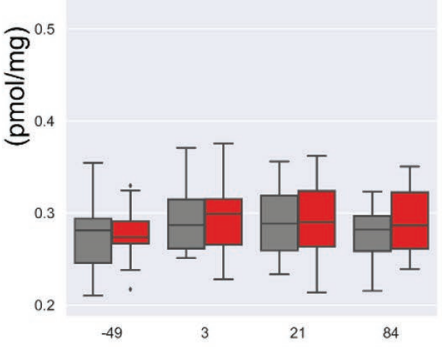

Days relative to calving

Figure 5. Concentrations of acylcarnitines (pmol $/ \mathrm{mg}$ ) in skeletal muscle of normal-conditioned (NBCS; $<3.5 \mathrm{BCS}$ or $<1.2 \mathrm{~cm}$ BFT) and over-conditioned (HBCS; $>3.75$ BCS or $>1.4 \mathrm{~cm}$ BFT) cows during the experimental period $(\mathrm{n}=19$ per group). Symbols indicate differences $\left({ }^{*} P<0.05\right)$ between the groups at a given time. Different uppercase letters $(\mathrm{A}, \mathrm{B})$ indicate differences between time points within HBCS cows, and different lowercase letters $(a, b)$ indicate differences between time points within NBCS cows. In each box plot, the heavy horizontal line crossing the box is the median, the bottom and top of the box are the lower and upper quartiles, and the whiskers follow the Tukey boxplot definition. 
during the periparturient period but decreased in serum in early lactation. This is consistent with the increased need for free carnitine to transfer LCFA originating from the intense lipomobilization in adipose tissue into the mitochondrial matrix to generate metabolic energy in dairy cows (Humer et al., 2016). In dairy cows, the
(C9)

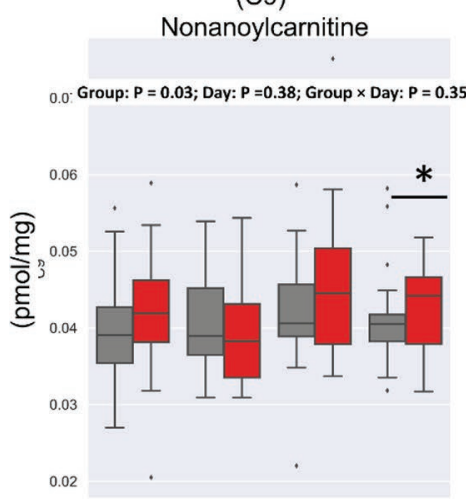

(C12-DC)

Dodecanoylcarnitine

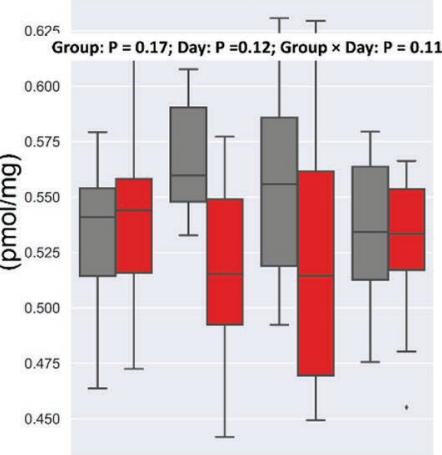

(C14:2)

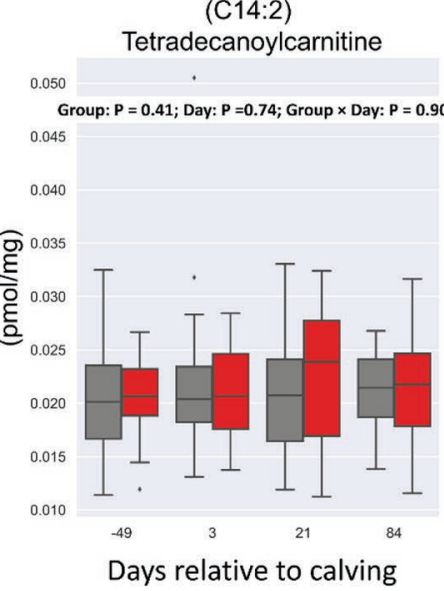

$\square$ HBCS $\square$ NBCS

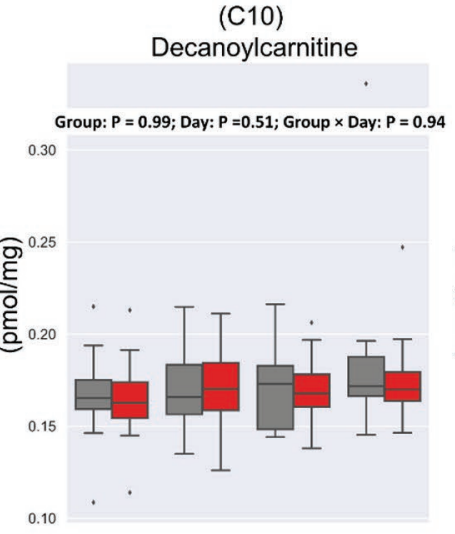

(C14:0)

Tetradecanoylcarnitine

C Group: $P=0.94 ;$ Day: $P=0.09 ;$ Group $\times$ Day: $P=0.85$

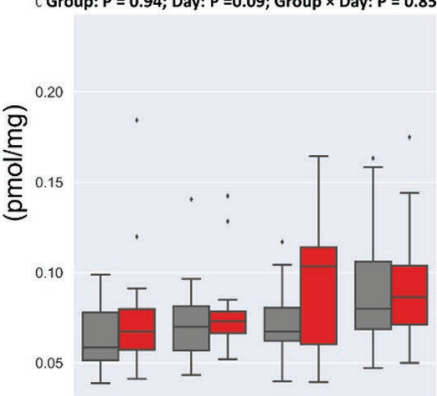

(C14:2)

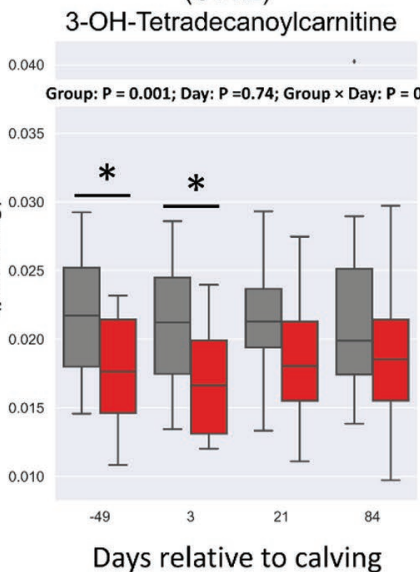

(C12)

Dodecanoylcarnitine

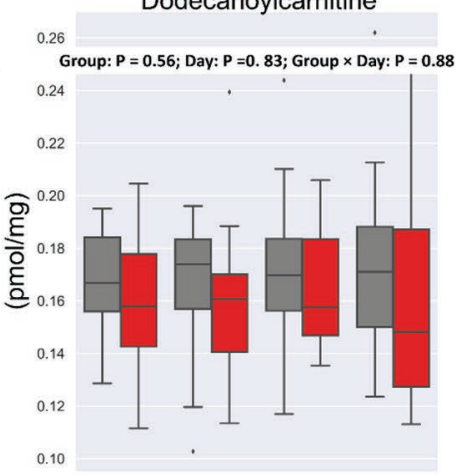

(C14:1)
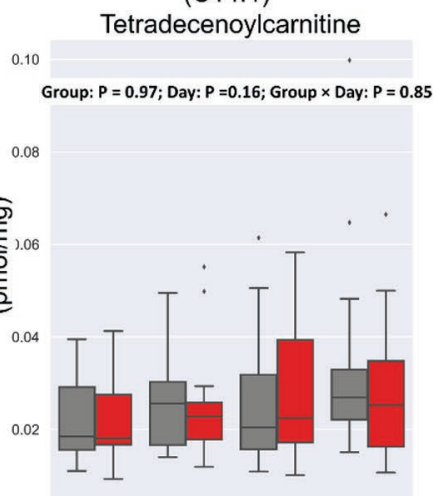

(C16:0)

Hexadecanoylcarnitine
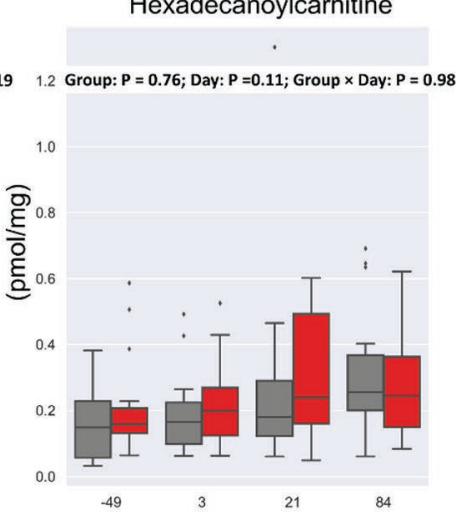

Days relative to calving

Figure 5 (Continued). Concentrations of acylcarnitines (pmol $/ \mathrm{mg}$ ) in skeletal muscle of normal-conditioned (NBCS; $<3.5 \mathrm{BCS}$ or $<1.2 \mathrm{~cm}$ BFT) and over-conditioned (HBCS; $>3.75$ BCS or $>1.4 \mathrm{~cm}$ BFT) cows during the experimental period ( $\mathrm{n}=19$ per group). Symbols indicate differences $\left({ }^{*} P<0.05\right)$ between the groups at a given time. Different uppercase letters $(\mathrm{A}, \mathrm{B})$ indicate differences between time points within HBCS cows, and different lowercase letters $(\mathrm{a}, \mathrm{b})$ indicate differences between time points within NBCS cows. In each box plot, the heavy horizontal line crossing the box is the median, the bottom and top of the box are the lower and upper quartiles, and the whiskers follow the Tukey boxplot definition. 
reduction in serum free-carnitine during early lactation is likely due to the intense uptake of free carnitine by skeletal muscle to maintain intracellular concentrations (Schooneman et al., 2014; Yang et al., 2019).
Acylcarnitines are intermediate FA esters that are formed from their respective acyl-CoA by both mitochondrial and peroxisomal enzymes for FAO (Rinaldo et al., 2002). Short-chain AcylCN have attracted in-

\section{HBCS $\square$ NBCS}
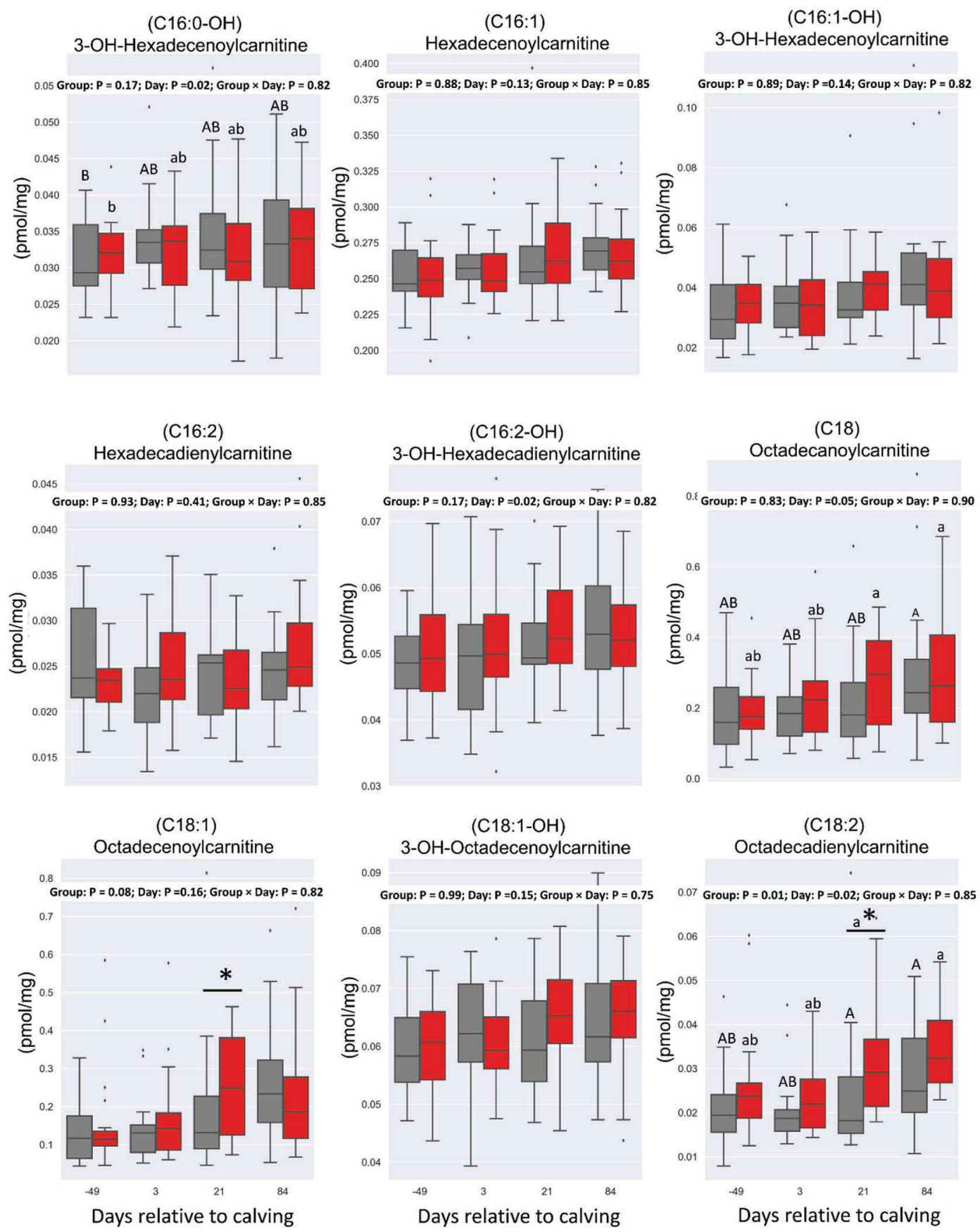

Figure 5 (Continued). Concentrations of acylcarnitines (pmol $/ \mathrm{mg}$ ) in skeletal muscle of normal-conditioned (NBCS; $<3.5 \mathrm{BCS}$ or $<1.2 \mathrm{~cm}$ BFT) and over-conditioned (HBCS; $>3.75$ BCS or $>1.4 \mathrm{~cm} \mathrm{BFT)}$ cows during the experimental period ( $\mathrm{n}=19$ per group). Symbols indicate differences $(* P<0.05)$ between the groups at a given time. Different uppercase letters $(\mathrm{A}, \mathrm{B})$ indicate differences between time points within HBCS cows, and different lowercase letters $(\mathrm{a}, \mathrm{b})$ indicate differences between time points within NBCS cows. In each box plot, the heavy horizontal line crossing the box is the median, the bottom and top of the box are the lower and upper quartiles, and the whiskers follow the Tukey boxplot definition. 


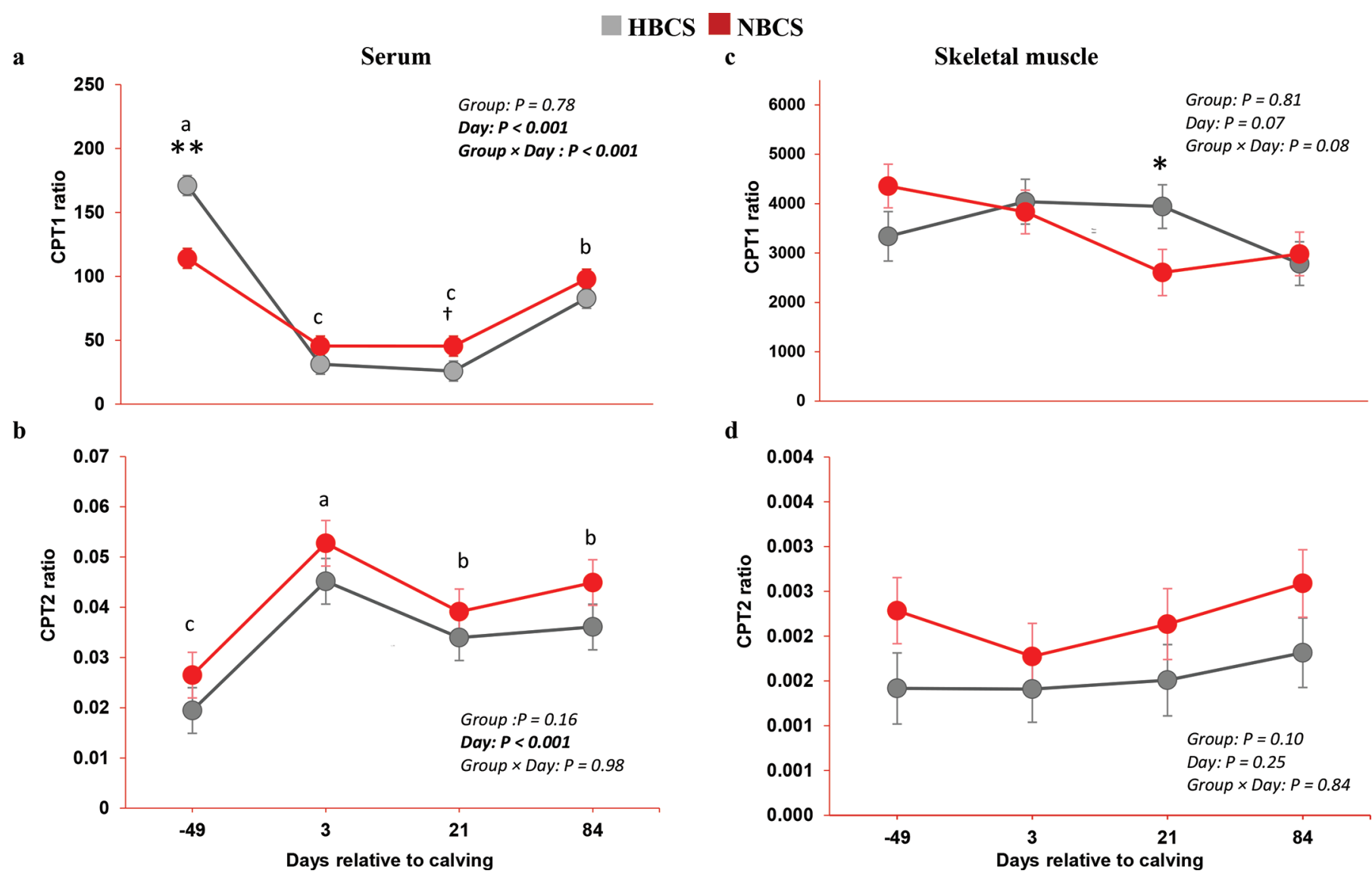

Figure 6. Carnitine palmitoyltransferase $(\mathrm{CPT}) 1$ and $\mathrm{CPT} 2$ ratios in serum and skeletal muscle in normal-conditioned (NBCS; $<3.5 \mathrm{BCS}$ or $<1.2 \mathrm{~cm} \mathrm{BFT}$ ) and over-conditioned (HBCS; $>3.75$ BCS or $>1.4 \mathrm{~cm} \mathrm{BFT)} \mathrm{cows} \mathrm{during} \mathrm{the} \mathrm{experimental} \mathrm{period} \mathrm{(n}=19$ per group). Symbols indicate a differences $\left({ }^{*} P<0.05 ;{ }^{* *} P<0.01\right)$ or a trend for a difference $(\dagger P<0.1)$ between the groups at a given time. Different lowercase letters $(\mathrm{a}-\mathrm{c})$ indicate differences between time points within NBCS cows. Data are presented as means $\pm \mathrm{SE}$.

creasing attention as biomarkers in human subjects with metabolic stress (Seiler et al., 2015). In the current study, muscle concentrations of acetylcarnitine and some long-chain AcylCN increased with time of lactation in both groups, pointing to elevated FA $\beta$-oxidation in muscle mitochondria relative to TCA cycle flux. In the present study, serum acetylcarnitine concentrations, the universal catabolic oxidation product of all metabolic substrates, were elevated in HBCS cows compared with NBCS cows on d 3 and 21. This increase in serum acetylcarnitine coincided with greater concentrations of serum NEFA in HBCS than in NBCS cows, which may be associated with a greater extent of mitochondrial overload and incomplete FAO, likely due to insufficient metabolic adaptation in response to a load of FA around parturition. This is also consistent with reports on high-mobilizing dairy cows that had greater concentrations of acetylcarnitine compared with low-mobilizing cows in early lactation (Humer et al., 2016).
Short-chain AcylCN are released from the liver into the circulation, whereas medium- and long-chain Ac$y l C N$ are released from the liver and muscle into the bloodstream, as reported in human studies (Schooneman et al., 2015; Xu et al., 2016). Unfortunately, we have no data regarding AcylCN concentrations in liver to verify this fact. In the current study, HBCS cows had elevated serum concentrations of some long-chain AcylCN species (C14, C18, and C18:1) compared with NBCS cows. We speculate that the increase in longchain AcylCN might mirror the increase in lipolysis and concomitant increase in $\beta$-oxidation rates that exceed those of the TCA cycle. The observed higher concentrations of long-chain AcylCN in the serum of HBCS cows are consistent with previous findings that mitochondrial stress induced by lipid overload is associated with incomplete $\mathrm{FAO}$ and spillover of AcylCN into the circulation (Koves et al., 2008; Mihalik et al., 2010).

The carnitine shuttle, which is composed mainly of CPT1 and CPT2, regulates the mitochondrial entry 
HBCS $\square$ NBCS

a

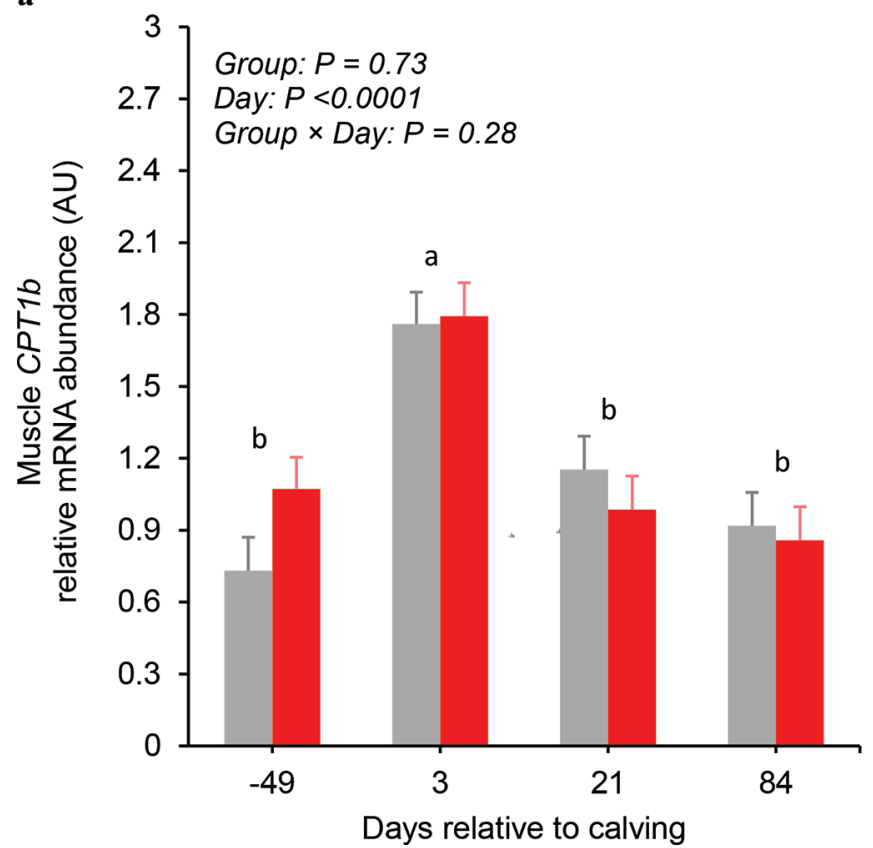

b

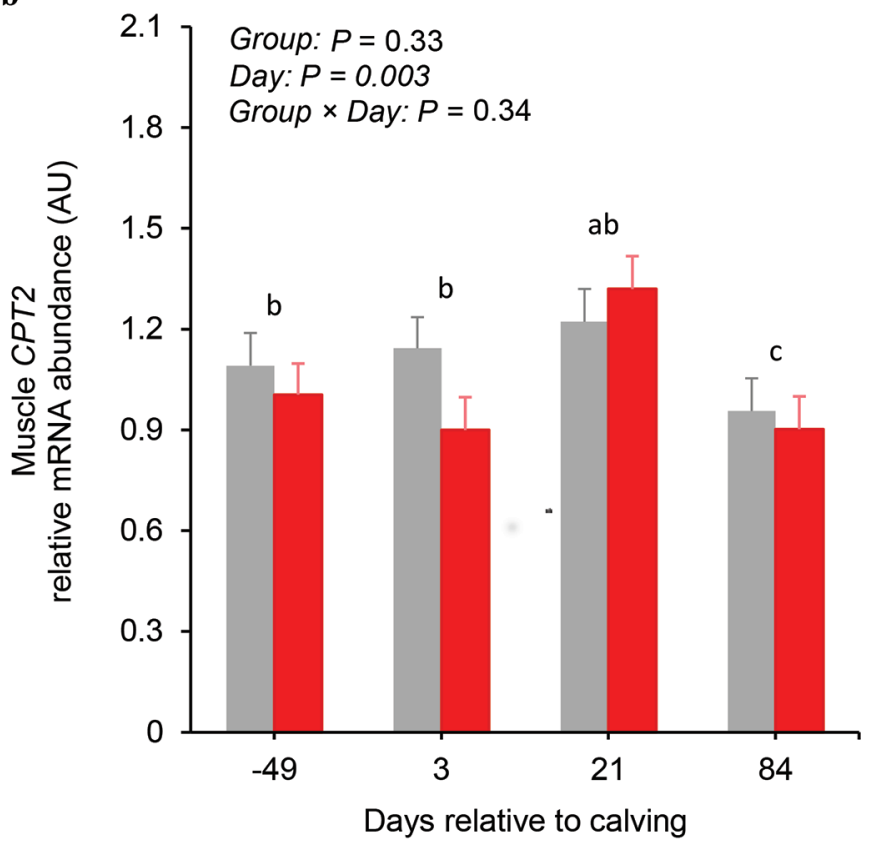

Figure 7. The mRNA abundance of carnitine palmitoyltransferase (CPT) $1 \mathrm{~b}$ and CPT2 (CPT1b and CPT2) in the skeletal muscle of normalconditioned (NBCS; $<3.5$ BCS or $<1.2 \mathrm{~cm} \mathrm{BFT}$ ) and over-conditioned (HBCS; $>3.75$ BCS or $>1.4 \mathrm{~cm}$ BFT) cows. Different lowercase letters $(\mathrm{a}-\mathrm{c})$ indicate differences between time points. Data are presented as means $\pm \mathrm{SE}$.

of acyl-CoA esters (Sigauke et al., 2003). The CPT1 enzyme is responsible for forming AcylCN to enter the outer mitochondrial membrane, and CPT2 accomplishes the reversal of this process and the translocation of Acyl-CoA to the inner mitochondrial membrane (Yaligar et al., 2016). In the current study, the CPT1 ratio, as a potential marker for CPT1 deficiency (Fingerhut et al., 2001), was evaluated. The CPT1 is considered a rate-limiting enzyme for long-chain FA entry into the mitochondria for $\beta$-oxidation (Jogl et al., 2004). Thus, an elevation of this ratio has been described in CPT1 deficiency (Fingerhut et al., 2001). The CPT1 ratio was reduced in early lactation in both serum and muscle (only in HBCS cows), reflecting the increased entrance of long-chain acyl-CoA into the mitochondria, which is in line with previous observations in dairy cows (Yang et al., 2019). Incomplete FA $\beta$-oxidation downstream of CPT1 is revealed by altered AcylCN levels (Koves et al., 2008), as acyl-CoA under mitochondrial FA overload can be converted into AcylCN for transport out of the mitochondria (Koves et al., 2008; Millington and Stevens, 2011; Violante et al., 2013). We also evaluated the CPT2 ratio as a potential marker to describe CPT2 deficiency (Gempel et al., 2002). Deficiency of CPT2 was associated with a pronounced increase of C16:0 and C18:1 AcylCN, whereas acetylcarnitine content was low, pointing toward a reduction in mitochondrial long-chain FAO (Gempel et al., 2002). In the current study, the serum CPT2 ratio was increased around parturition in both groups, probably reflecting CPT2 deficiency. In this situation, reconverting the long-chain AcylCN esters to their respective acyl-CoA is impaired, and $\mathrm{AcylCN}$ profiles in mitochondria are characterized by the accumulation of long-chain AcylCN, which are subsequently transported out of the mitochondria to the bloodstream (Flanagan et al., 2010; Schooneman et al., 2013). However, the mRNA abundance of $C P T 1 b$ (muscle isoform) and CPT2 in skeletal muscle remained unaffected by over-conditioning around calving. The mRNA data in muscle were not related to alterations of serum AcylCN, indicating that the metabolomics approach seems more suitable to identify metabolic changes. In both groups, the mRNA abundance of CPT1b increased from d -49 to $3 \mathrm{pp}$, followed by a decline thereafter, whereas the mRNA abundance of CPT2 increased from d 3 to $21 \mathrm{pp}$. These data may suggest a failed attempt to oxidize the excess of longchain fatty acyl-CoA to $\mathrm{CO}_{2}$ through the downstream $\beta$-oxidation (TCA cycle and respiratory chain) caused by mitochondrial overload.

Carnitine has a half-life of 1 to $2 \mathrm{~h}$ in the liver and there is a rapid exchange between plasma carnitine and 
liver carnitine (Bene et al., 2018). In contrast, carnitine in skeletal muscle does not readily communicate with plasma carnitine and has a half-life of several days (Koves et al., 2008). Therefore, changes in liver carnitine content appear rapidly in plasma, whereas changes in skeletal muscle carnitine content may not be as readily apparent in plasma (Steiber et al., 2004; Koves et al., 2008). Whether AcylCN act in the same manner, is unknown, to the best of our knowledge.

In this study, most of the medium- and long-chain AcylCN concentrations in muscle were unchanged by over-conditioning around calving, except for C12-DC and $\mathrm{C} 14: 2-\mathrm{OH}$, which did increase in early lactation in the muscle of HBCS cows. Elevated concentrations of long-chain AcylCN species around parturition in the skeletal muscle of dairy cows were observed previously (Yang et al., 2019). The concentrations of C14:2-OH on $\mathrm{d}-49$ and $\mathrm{d} 3$ were higher in the muscle of HBCS than NBCS cows. The long-chain AcylCN C14:2-OH is the carnitinated form of $\mathrm{C} 14: 2-\mathrm{OH}-\mathrm{CoA}$, an intermediate produced during $\beta$-oxidation of tetradecadienoic acid ( 1 cycle) or of linoleic acid in mice ( 2 cycles; Mirzoyan et al., 2017). In diabetic mice, C14:2-OH was shown to be positively correlated with urine albuminuria/ urine creatinine ratio (uACR), glomerular hypertrophy, blood glucose, and plasma lipids (Mirzoyan et al., 2017). In this study, HBCS cows had lower concentrations of C18:1 and C18:2 in muscle than NBCS cows. This decrease in muscle C18:2 in HBCS cows on d 21 coincided with a more negative EB and intense mobilization of body fat, as evidenced by greater BCS and BFT losses as well as elevated concentrations of NEFA and BHB in the serum of HBCS cows (Schuh et al., 2019). Thus, this metabolite might be an important marker of or contributor to underlying changes in the metabolism of skeletal muscle due to over-conditioning, which warrants further investigation. In summary, HBCS cows displayed higher concentrations of circulating acetylcarnitine and long-chain AcylCN in serum during early lactation that may reflect mitochondrial overload and incomplete FAO, being associated with over-conditioning in early lactation.

\section{CONCLUSIONS}

In this study, the greater concentrations of circulating acetylcarnitine and long-chain AcylCN in the serum of HBCS cows during early lactation point to mitochondrial overload and incomplete FAO being associated with over-conditioning in early lactation. Regardless of group, the mRNA abundance of $C P T 1 b$ and CPT2 increased from before calving to early lactation, followed by a decline to nearly antepartum values by $\mathrm{d}$ 84. Most of the medium- and long-chain AcylCN concentrations in skeletal muscle were unchanged by over-conditioning around calving, except for C12:1, C14:2-OH, and $\mathrm{C} 18: 2$, which increased in HBCS cows in early lactation. Overall, blood appears to be better reflect the overconditioning on AcylCN than muscle.

\section{ACKNOWLEDGMENTS}

The scholarship for K. Schuh by the H. Wilhelm Schaumann Foundation (Hamburg, Germany) is gratefully acknowledged. The study would not have been possible without the Educational and Research Centre for Animal Husbandry, Hofgut Neumuehle; they made the cows available and their staff supported the animal trial. We extend special gratitude to Isabella Israel and Inga Hofs (Institute of Animal Science, Physiology and Hygiene Unit, University of Bonn, Germany) for their excellent technical assistance. We also appreciate Dörte Frieten (Educational and Research Centre for Animal Husbandry, Hofgut Neumuehle) for her help during the sampling of the cows. The authors have stated no conflicts of interest.

\section{REFERENCES}

Bene, J., K. Hadzsiev, and B. Melegh. 2018. Role of carnitine and its derivatives in the development and management of type 2 diabetes. Nutr. Diabetes 8:8-18. https://doi.org/10.1038/s41387-018 $-0017-1$.

Bjørndal, B., E. K. Alteras, C. Lindquist, A. Svardal, J. Skorve, and R. K. Berge. 2018. Associations between fatty acid oxidation, hepatic mitochondrial function, and plasma acylcarnitine levels in mice. Nutr. Metab. (Lond.) 15:10-23. https://doi.org/10.1186/s12986 $-018-0241-7$.

Bustin, S. A., V. Benes, J. A. Garson, J. Hellemans, J. Huggett, M. Kubista, R. Mueller, T. Nolan, M. W. Pfaffl, G. L. Shipley, J. Vandesompele, and C. T. Wittwer. 2009. The MIQE guidelines: Minimum Information for Publication of Quantitative Real-time PCR Experiments. Clin. Chem. 55:611-622. https://doi.org/10 .1373/clinchem.2008.112797.

Chong, J., O. Soufan, C. Li, I. Caraus, S. Z. Li, G. Bourque, D. S. Wishart, and J. G. Xia. 2018. MetaboAnalyst 4.0: towards more transparent and integrative metabolomics analysis. Nucleic Acids Res. 46(W1):W486-W494. https://doi.org/10.1093/nar/gky310.

Dechow, C. D., G. W. Rogers, L. Klei, and T. J. Lawlor. 2004. Heritability and correlations for body condition score and dairy form within and across lactation and age. J. Dairy Sci. 87:717-728. https://doi.org/10.3168/jds.S0022-0302(04)73215-4.

Drackley, J. K., H. M. Dann, G. N. Douglas, N. A. J. Guretzky, N. B. Litherland, J. P. Underwood, and J. J. Loor. 2005. Physiological and pathological adaptations in dairy cows that may increase susceptibility to periparturient diseases and disorders. Ital. J. Anim. Sci. 4:323-344. https://doi.org/10.4081/ijas.2005.323.

Edmonson, A. J., I. J. Lean, L. D. Weaver, T. Farver, and G. Webster. 1989. A body condition scoring chart for Holstein dairy cows. J. Dairy Sci. 72:68-78. https://doi.org/10.3168/jds.S0022 -0302(89)79081-0.

EMEA (European Medicines Agency). 2011. Guideline on bioanalytical method validation. Accessed Aug. 23, 2019. https://www.ema .europa.eu/en/documents/scientific-guideline/guideline -bioanalytical-method-validation_en.pdf.

Fingerhut, R., W. Roschinger, A. C. Muntau, T. Dame, J. Kreischer, R. Arnecke, A. Superti-Furga, H. Troxler, B. Liebl, B. Olgemoller, 
and A. A. Roscher. 2001. Hepatic carnitine palmitoyltransferase I deficiency: Acylcarnitine profiles in blood spots are highly specific. Clin. Chem. 47:1763-1768.

Flanagan, J. L., P. A. Simmons, J. Vehige, M. D. P. Willcox, and Q. Garrett. 2010. Role of carnitine in disease. Nutr. Metab. (Lond.) 7:30-44. https://doi.org/10.1186/1743-7075-7-30.

Gempel, K., S. Kiechl, S. Hofmann, H. Lochmuller, U. Kiechl-Kohlendorfer, J. Willeit, W. Sperl, A. Rettinger, I. Bieger, D. Pongratz, K. D. Gerbitz, and M. F. Bauer. 2002. Screening for carnitine palmitoyltransferase II deficiency by tandem mass spectrometry. J. Inherit. Metab. Dis. 25:17-27. https://doi.org/10.1023/A: 1015109127986

GfE (German Society of Nutrition Physiology). 2001. Empfehlungen zur Energie- und Nährstoffversorgung der Milchkühe und Aufzuchtrinder [Recommended energy and nutrient supply for dairy cows and heifers]. Ausschuss für Bedarfsnormen der Gesellschaft für Ernährungsphysiologie No. 8. DLG Verlag, Frankfurt am Main, Germany.

Ghaffari, M. H., A. Jahanbekam, H. Sadri, K. Schuh, G. Dusel, C. Prehn, J. Adamski, C. Koch, and H. Sauerwein. 2019. Metabolomics meets machine learning: Longitudinal metabolite profiling in serum of normal versus overconditioned cows and pathway analysis. J. Dairy Sci. 102:11561-11585. https://doi.org/10.3168/ jds.2019-17114.

Hellemans, J., G. Mortier, A. De Paepe, F. Speleman, and J. Vandesompele. 2007. qBase relative quantification framework and software for management and automated analysis of real-time quantitative PCR data. Genome Biol. 8:R19-33. https://doi.org/10 .1186 /gb-2007-8-2-r19.

Humer, E., A. Khol-Parisini, B. U. Metzler-Zebeli, L. Gruber, and Q. Zebeli. 2016. Alterations of the lipid metabolome in dairy cows experiencing excessive lipolysis early postpartum. PLoS One 11:e0158633. https://doi.org/10.1371/journal.pone.0158633.

Jogl, G., Y. S. Hsiao, and L. Tong. 2004. Structure and function of carnitine acyltransferases. Ann. N. Y. Acad. Sci. 1033:17-29. https:/ /doi.org/10.1196/annals.1320.002.

Kinoshita, A., A. Kenez, M. Hasselmann, S. Danicke, and K. Huber. 2018. Inter-individual variation in adaptive capacity at onset of lactation: Linking metabolic phenotype with mitochondrial DNA haplotype in Holstein dairy cows. Sci. Rep. 8:15439. https://doi .org/10.1038/s41598-018-33853-6.

Koves, T. R., J. R. Ussher, R. C. Noland, D. Slentz, M. Mosedale, O. Ilkayeva, J. Bain, R. Stevens, J. R. Dyck, C. B. Newgard, G. D. Lopaschuk, and D. M. Muoio. 2008. Mitochondrial overload and incomplete fatty acid oxidation contribute to skeletal muscle insulin resistance. Cell Metab. 7:45-56. https://doi.org/10.1016/j .cmet.2007.10.013.

Makrecka-Kuka, M., E. Sevostjanovs, K. Vilks, K. Volska, U. Antone, J. Kuka, E. Makarova, O. Pugovics, M. Dambrova, and E. Liepinsh. 2017. Plasma acylcarnitine concentrations reflect the acylcarnitine profile in cardiac tissues. Sci. Rep. 7:17528. https://doi .org/10.1038/s41598-017-17797-x.

McCoin, C. S., T. A. Knotts, and S. H. Adams. 2015. Acylcarnitinesold actors auditioning for new roles in metabolic physiology. Nat. Rev. Endocrinol. 11:617-625. https://doi.org/10.1038/nrendo .2015 .129 .

Mihalik, S. J., B. H. Goodpaster, D. E. Kelley, D. H. Chace, J. Vockley, F. G. Toledo, and J. P. DeLany. 2010. Increased levels of plasma acylcarnitines in obesity and type 2 diabetes and identification of a marker of glucolipotoxicity. Obesity (Silver Spring) 18:1695-1700. https://doi.org/10.1038/oby.2009.510.

Millington, D. S., and R. D. Stevens. 2011. Acylcarnitines: Analysis in plasma and whole blood using tandem mass spectrometry. Methods Mol. Biol. 708:55-72. https://doi.org/10.1007/978-1-61737 -985-7_3.

Mirzoyan, K., K. Klavins, T. Koal, M. Gillet, D. Marsal, C. Denis, J. Klein, J. L. Bascands, J. P. Schanstra, and J. S. Saulnier-Blache. 2017. Increased urine acylcarnitines in diabetic ApoE-/- mice: Hydroxytetradecadienoylcarnitine $(\mathrm{C} 14: 2-\mathrm{OH})$ reflects diabetic nephropathy in a context of hyperlipidemia. Biochem. Biophys.
Res. Commun. 487:109-115. https://doi.org/10.1016/j.bbrc.2017 .04 .026 .

Ospina, P. A., D. V. Nydam, T. Stokol, and T. R. Overton. 2010. Evaluation of nonesterified fatty acids and beta-hydroxybutyrate in transition dairy cattle in the northeastern United States: Critical thresholds for prediction of clinical diseases. J. Dairy Sci. 93:546-554. https://doi.org/10.3168/jds.2009-2277.

Ramos-Roman, M. A., L. Sweetman, M. J. Valdez, and E. J. Parks. 2012. Postprandial changes in plasma acylcarnitine concentrations as markers of fatty acid flux in overweight and obesity. Metabolism 61:202-212. https://doi.org/10.1016/j.metabol.2011.06.008.

Rico, J. E., Y. Zang, N. J. Haughey, A. G. Rius, and J. W. McFadden. 2018. Short communication: Circulating fatty acylcarnitines are elevated in overweight periparturient dairy cows in association with sphingolipid biomarkers of insulin resistance. J. Dairy Sci. 101:812-819. https://doi.org/10.3168/jds.2017-13171.

Rinaldo, P., D. Matern, and M. J. Bennett. 2002. Fatty acid oxidation disorders. Annu. Rev. Physiol. 64:477-502. https://doi.org/10 .1146/annurev.physiol.64.082201.154705.

Römisch-Margl, W., C. Prehn, R. Bogumil, C. Rohring, K. Suhre, and J. Adamski. 2012. Procedure for tissue sample preparation and metabolite extraction for high-throughput targeted metabolomics. Metabolomics 8:133-142. https://doi.org/10.1007/s11306 -011-0293-4.

Saremi, B., H. Sauerwein, S. Danicke, and M. Mielenz. 2012. Technical note: Identification of reference genes for gene expression studies in different bovine tissues focusing on different fat depots. J. Dairy Sci. 95:3131-3138. https://doi.org/10.3168/jds.2011-4803.

Schooneman, M. G., N. Achterkamp, C. A. Argmann, M. R. Soeters, and S. M. Houten. 2014. Plasma acylcarnitines inadequately reflect tissue acylcarnitine metabolism. Biochim. Biophys. Acta 1841:987-994. https://doi.org/10.1016/j.bbalip.2014.04.001.

Schooneman, M. G., R. H. Houtkooper, C. E. Hollak, R. J. Wanders, F. M. Vaz, M. R. Soeters, and S. M. Houten. 2016. The impact of altered carnitine availability on acylcarnitine metabolism, energy expenditure and glucose tolerance in diet-induced obese mice. Biochim. Biophys. Acta 1862:1375-1382. https://doi.org/10.1016/ j.bbadis.2016.04.012.

Schooneman, M. G., G. A. Ten Have, N. van Vlies, S. M. Houten, N. E. Deutz, and M. R. Soeters. 2015. Transorgan fluxes in a porcine model reveal a central role for liver in acylcarnitine metabolism. Am. J. Physiol. Endocrinol. Metab. 309:E256-E264. https://doi .org/10.1152/ajpendo.00503.2014.

Schooneman, M. G., F. M. Vaz, S. M. Houten, and M. R. Soeters. 2013. Acylcarnitines: Reflecting or inflicting insulin resistance? Diabetes 62:1-8. https://doi.org/10.2337/db12-0466.

Schuh, K., H. Sadri, S. Häussler, L. A. Webb, C. Urh, M. Wagner, C. Koch, J. Frahm, S. Dänicke, G. Dusel, and H. Sauerwein. 2019. Comparison of performance and metabolism from late pregnancy to early lactation in dairy cows with elevated versus normal body condition at dry-off. Animal 13:1478-1488. https://doi.org/10 .1017/S1751731118003385.

Schulz, K., J. Frahm, U. Meyer, S. Kersten, D. Reiche, J. Rehage, and S. Danicke. 2014. Effects of prepartal body condition score and peripartal energy supply of dairy cows on postpartal lipolysis, energy balance and ketogenesis: An animal model to investigate subclinical ketosis. J. Dairy Res. 81:257-266. https://doi.org/10 $.1017 /$ S0022029914000107.

Seiler, S. E., T. R. Koves, J. R. Gooding, K. E. Wong, R. D. Stevens, O. R. Ilkayeva, A. H. Wittmann, K. L. DeBalsi, M. N. Davies, L. Lindeboom, P. Schrauwen, V. B. Schrauwen-Hinderling, and D. M. Muoio. 2015. Carnitine acetyltransferase mitigates metabolic inertia and muscle fatigue during exercise. Cell Metab. 22:65-76. https://doi.org/10.1016/j.cmet.2015.06.003.

Sigauke, E., D. Rakheja, K. Kitson, and M. J. Bennett. 2003. Carnitine palmitoyltransferase II deficiency: A clinical, biochemical, and molecular review. Lab. Invest. 83:1543-1554. https://doi.org/ 10.1097/01.LAB.0000098428.51765.83.

Simcox, J., G. Geoghegan, J. A. Maschek, C. L. Bensard, M. Pasquali, R. Miao, S. Lee, L. Jiang, I. Huck, E. E. Kershaw, A. J. Donato, U. 
Apte, N. Longo, J. Rutter, R. Schreiber, R. Zechner, J. Cox, and C. J. Villanueva. 2017. Global analysis of plasma lipids identifies liver-derived acylcarnitines as a fuel source for brown fat thermogenesis. Cell Metab. 26:509-522.e6. https://doi.org/10.1016/j .cmet.2017.08.006.

Steiber, A., J. Kerner, and C. L. Hoppel. 2004. Carnitine: A nutritional, biosynthetic, and functional perspective. Mol. Aspects Med. 25:455-473. https://doi.org/10.1016/j.mam.2004.06.006.

Szymańska, E., E. Saccenti, A. K. Smilde, and J. A. Westerhuis. 2012. Double-check: Validation of diagnostic statistics for PLS-DA models in metabolomics studies. Metabolomics 8(Suppl. 1):3-16. https: //doi.org/10.1007/s11306-011-0330-3.

van den Berg, R. A., H. C. Hoefsloot, J. A. Westerhuis, A. K. Smilde, and M. J. van der Werf. 2006. Centering, scaling, and transformations: Improving the biological information content of metabolomics data. BMC Genomics 7:142-157. https://doi.org/10.1186/ 1471-2164-7-142.

Vaz, F. M., and R. J. A. Wanders. 2002. Carnitine biosynthesis in mammals. Biochem. J. 361:417-429. https://doi.org/10.1042/ bj3610417.

Violante, S., L. Ijlst, H. Te Brinke, I. Tavares de Almeida, R. J. Wanders, F. V. Ventura, and S. M. Houten. 2013. Carnitine palmitoyltransferase 2 and carnitine/acylcarnitine translocase are involved in the mitochondrial synthesis and export of acylcarnitines. FASEB J. 27:2039-2044. https://doi.org/10.1096/fj.12-216689.

Weber, M., L. Locher, K. Huber, A. Kenez, J. Rehage, R. Tienken, U. Meyer, S. Danicke, H. Sauerwein, and M. Mielenz. 2016. Longitudinal changes in adipose tissue of dairy cows from late pregnancy to lactation. Part 1: The adipokines apelin and resistin and their relationship to receptors linked with lipolysis. J. Dairy Sci. 99:1549-1559. https://doi.org/10.3168/jds.2015-10131.
Xu, C. A., Z. Wang, R. H. Zhang, H. Y. Zhang, S. X. Fu, and C. Xia. 2011. Effect of NEFA and glucose levels on CPT-I mRNA expression and translation in cultured bovine hepatocytes. J. Vet. Med. Sci. 73:97-101. https://doi.org/10.1292/jvms.10-0164.

Xu, G., J. S. Hansen, X. J. Zhao, S. Chen, M. Hoene, X. L. Wang, J. O. Clemmesen, N. H. Secher, H. U. Haring, B. K. Pedersen, R. Lehmann, C. Weigert, and P. Plomgaard. 2016. Liver and muscle contribute differently to the plasma acylcarnitine pool during fasting and exercise in humans. J. Clin. Endocrinol. Metab. 101:50445052. https://doi.org/10.1210/jc.2016-1859.

Yaligar, J., W. W. Teoh, R. Othman, S. K. Verma, B. H. Phang, S. S. Lee, W. W. Wang, H. C. Toh, V. Gopalan, K. Sabapathy, and S. S. Velan. 2016. Longitudinal metabolic imaging of hepatocellular carcinoma in transgenic mouse models identifies acylcarnitine as a potential biomarker for early detection. Sci. Rep. 6:20299. https:/ /doi.org/10.1038/srep20299.

Yang, Y., H. Sadri, C. Prehn, J. Adamski, J. Rehage, S. Danicke, B. Saremi, and H. Sauerwein. 2019. Acylcarnitine profiles in serum and muscle of dairy cows receiving conjugated linoleic acids or a control fat supplement during early lactation. J. Dairy Sci. 102:754-767. https://doi.org/10.3168/jds.2018-14685.

Zukunft, S., C. Prehn, C. Rohring, G. Moller, M. Hrabe de Angelis, J. Adamski, and J. Tokarz. 2018. High-throughput extraction and quantification method for targeted metabolomics in murine tissues. Metabolomics 14:18. https://doi.org/10.1007/s11306-017 $-1312-\mathrm{x}$.

Zukunft, S., M. Sorgenfrei, C. Prehn, G. Moller, and J. Adamski. 2013. Targeted metabolomics of dried blood spot extracts. Chromatographia 76:1295-1305. https://doi.org/10.1007/s10337-013-2429-3. 